\title{
Evidence of lateral transmission of aggressive features between different types of breast cancer cells
}

\author{
NANCY ADRIANA ESPINOZA-SÁNCHEZ ${ }^{1,2}$, EDUARDO VADILLO ${ }^{3}$, JUAN CARLOS BALANDRÁN $^{3,4}$, \\ ALBERTO MONROY-GARCÍA ${ }^{4}$, ROSANA PELAYO ${ }^{4}$ and EZEQUIEL M. FUENTES-PANANÁ ${ }^{2}$ \\ ${ }^{1} \mathrm{PhD}$ Program in Biomedical Science, Medicine Faculty, National Autonomous University of Mexico, University City, \\ Mexico City 04510; ${ }^{2}$ Virology and Cancer Research Unit, Children's Hospital of Mexico Federico Gómez, \\ Mexico City 06720; ${ }^{3}$ Department of Molecular Biomedicine, Centre for Investigation and Advanced Studies \\ of the National Polytechnic Institute (CINVESTAV-IPN), Mexico City 07360; ${ }^{4}$ Oncology Research Unit, \\ Oncology Hospital, Mexican Institute for Social Security, Mexico City 06720, Mexico
}

Received June 21, 2017; Accepted September 8, 2017

DOI: $10.3892 /$ ijo.2017.4128

\begin{abstract}
Breast cancer $(\mathrm{BrC})$ is a major public health problem worldwide. The intra-tumoral heterogeneity and tumor cell plasticity importantly contribute to disease progression and treatment failure. However, the dynamic interactions between different tumor clones, as well as their contribution to tumor aggressiveness are still poorly understood. In this study, we provide evidence of a lateral transmission of aggressive features between aggressive and non-aggressive tumor cells, consisting of gain of expression of cancer stem cell markers, increased expression of CXCL12 receptors CXCR4 and CXCR7 and increased invasiveness in response to CXCL12, which correlated with high levels of secretion of pro-inflammatory mediators G-CSF, GM-CSF, MCP-1, IL- 8 and metalloproteinases 1 and 2 by the aggressive cells. Noteworthy, we found no evidence of a TGF- $\beta$ participation in the inducible-invasive phenotype. Altogether, our results provide evidence of communication between tumor cells with different potentials for aggressiveness, which could influence intra-tumoral population dynamics promoting the emergence of clones with novel functions. Understanding these interactions will provide better targets for diagnosis, prognosis and therapeutic strategies.
\end{abstract}

\section{Introduction}

Cancer is one of the leading human health problems worldwide. Since the term includes an extensive variety of different

Correspondence to: Dr Ezequiel M. Fuentes-Pananá, Unidad de Investigación Médica en Virología y Cáncer, Hospital Infantil de México Federico Gómez, Dr. Márquez 162, Colonia Doctores, Mexico City 06720, Mexico

E-mail: empanana@yahoo.com; ezequiel.fuentes@alumni.bcm.edu

Key words: intra-tumoral communication, tumor aggression, invasion, pro-inflammatory cytokines, CXCL12 diseases, there are still many types of cancer with a dismal prognosis. Breast cancer ( $\mathrm{BrC})$ is the most common cause of cancer in working age women. Since most cases are diagnosed at advanced stages, $\mathrm{BrC}$ mortality is particularly high in underdeveloped countries $(1,2)$. Similar to most cancers, $\mathrm{BrC}$ is a highly heterogeneous disease, and although we currently have several classification and staging strategies to distinguish $\mathrm{BrC}$ sub-types with variable clinical outcomes, diseases originally thought as non-aggressive are often treatment resistant or relapse with highly aggressive characteristics (3). BrC cells also exhibit a large genetic and epigenetic intra-tumoral heterogeneity, conferring individual cells with specific immunosuppressive, proliferative, survival, metabolic, and invasive characteristics, that signal specific tumor clones with cancer dissemination and treatment resistance capacities (4). Furthermore, tumor clones are surrounded by a highly dynamic microenvironment formed by tumor-associated macrophages, neutrophils, T-cells, NK cells, fibroblasts, among other cells (the tumor microenvironment or TME). Although, in recent years we have seen a hefty increase in our understanding of critical interactions between tumor cells and TME cells, that has propelled the design of therapeutic molecular inhibitors (5), we significantly lack behind in our comprehension of relevant interactions between tumor clones with different aggressive features and the impact of these interactions on disease progression and prognosis.

Miller et al in a 1983 hallmark study observed that there is cooperation between metastatic and non-metastatic tumor clones. This group reported in a syngeneic mouse model that the presence of a metastatic subpopulation enabled non-mobile subpopulations to metastasize (6). More recently, a similar observation was also made by Calbo et al (7). Experiments using the Drosophila melanogaster (fruit fly) in which different cells were engineered to express either RAS ${ }^{V 12}$ or $s c r i b^{-}$common oncogenic mutations, revealed intra-clonal cooperation that promoted tumor growth and invasion (8). Similarly, Cleary et al observed in a mouse model of $\mathrm{BrC}$ that two different cellular clones had to be transferred to propagate the tumor in new mice, one clone with an Hras genetic mutation and the other with the capacity to secrete high levels of the 
Wntl signaling molecule but harboring a wild-type Hras (9). Soluble factors secreted by chemoresistant tumor cells and also by cancer stem cells (CSCs) promote resistance of chemosensitive cancer cells (10). Moreover, Mukherjee et al showed that non-migratory CSCs confer metastatic potential to non-CSCs (11).

Understanding the origin of intra-tumoral heterogeneity is one of the greatest challenges nowadays. There is evidence supporting tumor cell plasticity to microenvironmental stimuli and to genetic and epigenetic changes. Differentiated tumor cells seem able to acquire stem cell-like properties, and conversely, CSCs can lose stemness and form more differentiated populations (12). This bi-directionality among highly adaptable cells shapes the tumor with highly organized cell populations that directly impact disease evolution and prognosis (13). The epithelial to mesenchymal transition (EMT) is a conserved embryonic developmental process that also occurs in cancer. During EMT, epithelial cells lose their typical adhesive characteristics while gaining properties more related to mesenchymal mobile cells (14). The best-understood biomolecule associated with triggering EMT is TGF- $\beta$ (transforming growth factor- $\beta$ ), and mounting evidence supports a TGF- $\beta$ role in cancer cell invasion, metastasis, chemoresistance and relapse (15). EMT has been shown to correlate with acquisition of a CSC-like phenotype $(16,17)$, and circulating $\mathrm{BrC}$ cells often share characteristics of both stem-like cells and of EMT cells (18).

In this study, we report dynamic interactions between $\mathrm{BrC}$ cells with different aggressive potential leading to lateral transmission of aggressive features. We used four $\mathrm{BrC}$ cell lines, two characterized by an epithelial phenotype and the inability to induce metastasis in mice (MCF-7 and T47D; identified therein as non-aggressive or NA-BrC cells) and two with a mesenchymal phenotype and highly metastatic potential (HS578T and MDA-MB-231; identified as highly aggressive or $\mathrm{HA}-\mathrm{BrC}$ cells). We found that aggressive cells promoted an EMT/CSC-like and invasive phenotype in nonaggressive cells. Altogether, the experimental observations fit within a molecular regulatory network in which G-CSF, GM-CSF, IL-8 and MCP-1 inflammatory cytokines induce a stem-like invasive phenotype in NA-BrC cells, which respond increasing the activity of the CXCL12/CXCR4/CXCR7 chemokine signaling axis.

\section{Materials and methods}

Cell culture. All cell lines were obtained from the American Type Culture Collection (ATCC). Culture media and supplements were obtained from Gibco BRL Life Technologies. BrC cells were estrogen receptor (ER)-positive cells MCF-7 and T47D, and triple-negative HS578T and MDA-MB-231. MCF-7 (HTB-22) and HS578T (HTB-126) were cultured in Dulbecco's modified Eagle's medium (DMEM) with High Glucose (4.5 g/l) (ref. 11965-092), T47D (HTB-133) with RPMI-1640 medium (ref. 11875-093) and MDA-MB-231 (CRM-HTB-26) were cultured in Dulbecco's modified Eagle's medium with Nutrient Mixture F-12 (DMEM/F12, ref. 11039-021), the media were supplemented with $10 \%$ fetal bovine serum (FBS) (ref. 16000-044), $100 \mathrm{U} / \mathrm{ml}$ penicillin, $100 \mu \mathrm{g} / \mathrm{ml}$ streptomycin, and $0.25 \mu \mathrm{g} / \mathrm{ml}$ fungizone (ref. 15240-062) and were cultured at $37^{\circ} \mathrm{C}$ in $5 \% \mathrm{CO}_{2}$. All $\mathrm{BrC}$ cell lines were submitted to short tandem repeat analysis to verify the authenticity of each cell line. To obtain conditioned media $2 \times 10^{6}$ cells of each cell line were plated in $182 \mathrm{~cm}^{2}$ flasks in their standard supplemented medium. Supernatants were discarded when cultures reached $80 \%$ of confluence, cells were rinsed with PBS 1X (Phosphate Buffered Saline, Gibco, ref. 20012-027), and then $30 \mathrm{ml}$ of their respective culture media without FBS was added. Conditioned media were harvested after incubation for an additional $48 \mathrm{~h}$, centrifuged at $1500 \mathrm{rpm} / 5 \mathrm{~min}$, aliquoted, and stored at $-20^{\circ} \mathrm{C}$ until use.

Sera from breast cancer patients. Sera from $\mathrm{BrC}$ patients and healthy blood donors (controls) were obtained from the tissues and sera bank of the Unidad de Investigación en Virología y Cáncer, Hospital Infantil de México Federico Gómez. This study was approved by the Scientific, Ethical and Biosecurity Review Boards of the Hospital Infantil de México Federico Gómez (Comité de Investigación, Comité de Ética en Investigación and Comité de Bioseguridad). All patients and healthy controls were prospectively enrolled and were informed about the nature of the study. Those willing to participate signed a written informed consent prior to specimen collection and were treated according to the ethical guidelines and best clinical practice of our institution. The identity of the participants' names was anonymized for the duration of the study. Patients were on average 55.5 years old (range: $37-88$ ), 22 were diagnosed with invasive ductal carcinoma, 2 with lobular and 4 with mixed carcinoma, and they had not received neoadjuvant therapy at the time of sample collection. All patients were classified as luminal A, luminal B, Her-2 positive and triple-negative and as clinical stages I, II, and III, except for 4 patients for whom we could not obtain this information. Consecutive numbers were given to the samples as they were collected.

Induction of the invasive/stemness phenotype. $\mathrm{BrC}$ cells were plated at a density of $3 \times 10^{5}$ cells $/ \mathrm{ml} /$ well in 6-well flat bottom culture plates. Once cells attached to the plate, supernatants were discarded, cells were rinsed with PBS 1X, and then cultured with $3 \mathrm{ml}$ of conditioned media or with their respective media supplemented with 5,10 or $20 \mathrm{ng} / \mathrm{ml}$ of human recombinant TGF- $\beta$ (ref. 100-21) or $100 \mathrm{ng} / \mathrm{ml}$ of the following cytokines: G-CSF (ref. 300-23), GM-CSF (ref. 300-03), IL-8 (ref. 200-08) and MCP-1 (ref. 300-04) (all cytokines were from PeproTech) individually or all combined in a cocktail of cytokines. After incubation for $72 \mathrm{~h}$ cells were harvested for analyses. To neutralize the biological activity of TGF- $\beta$ of the HA-CMs, $2 \mu \mathrm{g} / \mathrm{ml}$ of the rabbit anti-human TGF- $\beta 1$, anti- $\beta 2$, and anti- $\beta 3$ neutralizing antibody (anti-TGF- $\beta$, R\&D Systems, Inc., ref. MAB1835) were added according to the guideline provided by the manufacturer.

Immunofluorescence. Cells $\left(3 \times 10^{4}\right)$ were seeded on coverslips for $24 \mathrm{~h}$, the invasive/stemness phenotype was experimentally induced as explained above, after which cells were fixed with paraformaldehyde $4 \%$ for $10 \mathrm{~min}$, and permeabilized with $0.2 \%$ Triton $\mathrm{X}-100$ in PBS for $20 \mathrm{~min}$. Cells were blocked for $1 \mathrm{~h}$ and then stained overnight at $4^{\circ} \mathrm{C}$ with the primary antibodies: mouse monoclonal anti-E-cadherin 
(1:100, Clone: 36/E-cadherin, BD Biosciences. ref. 610181), rabbit monoclonal anti-vimentin-Alexa Fluor-594 (1:1000, Clone: EPR3776. ref. ab154207), rabbit polyclonal anti-Oct4 (1:100, ref. ab18976) or rabbit polyclonal anti-Sox 2 (1:100, ref. ab97959); all antibodies were from Abcam. After that, cells were incubated for $30 \mathrm{~min}$ with the secondary antibodies: goat anti-mouse-IgG-FITC (1:500 Sigma-Aldrich Co., ref. F0257) or donkey anti-rabbit-FITC (1:500, Jackson ImmunoResearch Laboratories, ref. 711-095-152). Finally, nuclei were stained with DAPI (4',6-diamidino-2-phenylindole dihydrochloride; Thermo Fisher Scientific, ref. D1306) for 25 min. Cells were observed using a fluorescence microscope Olympus BX51 and images were acquired with a digital camera (Camedia C4040, Olympus). FITC staining intensity was quantified using the Image Pro Plus software, and the integrated optical density (IOD) of green cells was obtained.

Flow cytometry. For extracellular staining $3 \times 10^{5}$ cells were blocked with an unspecific IgG antibody 1:100 diluted in PBS $1 \mathrm{X}$ supplemented with $3 \%$ FBS for 15 min and then incubated for 30 min with mouse monoclonal anti-human CXCR3-PE-Cy7 (1:50, Clone: 1C6/CXCR3, ref. 560831), CXCR4-PE-Cy7 (1:50, Clone: 12G5, ref. 560669), CXCR7-APC (1:50, Clone: 10D1-J16, ref. 391406), CCR7-Alexa 647 (1:50, Clone: 150503, ref. 560816), CD44-PE (1:50, Clone: G44-26, 555479) (all antibodies were from BD Biosciences; except for anti-CXCR7 that was from BioLegend). Finally, cells were incubated with 7AAD (7-amino-actinomycin, BD Biosciences, ref. 559925). For intracellular staining cells were blocked with an unspecific IgG antibody 1:100, diluted in PBS 1X supplemented with 3\% FBS, then cells were washed with Phosflow Perm/Wash Buffer I (1X) (PWB 1X; BD Biosciences, ref. 557885), and fixed and permeabilized using Cytofix/Cytoperm solution (BD Biosciences, ref. 554722). To block intracellular Fc receptors the cells were again incubated with the unspecific IgG antibody, and then incubated for $1 \mathrm{~h}$ with mouse monoclonal anti-human Sox-2-Alexa 488 (Clone: 245610, BD Biosciences, ref. 560301). All acquisitions were performed on a FACSAria flow cytometer (Becton Dickinson). Analysis of flow cytometry data was performed on viable 7-AAD negative cells (except for Sox-2 staining) using FlowJo V10 software (Tree Star, Inc.).

Invasion assay. Cells $\left(2 \times 10^{4}\right)$ were resuspended in $200 \mu \mathrm{l}$ of their respective media with or without FBS and placed in the upper chamber of a Transwell [6.5-mm diameter, $8 \mu \mathrm{m}$ pore size (Corning Inc.) filled with Matrigel (Corning Inc., ref. 356237)]. Then, the Transwells were placed in a 24 -well culture dish containing $800 \mu \mathrm{l}$ of their respective media supplemented with any of the following chemoattractants: $10 \% \mathrm{FBS}$, the different CMs or $100 \mathrm{ng} / \mathrm{ml}$ of CXCL12 (C-X-C motif chemokine ligand 12, also known as SDF-1 $\alpha$, PeproTech, ref. 300-28A). To neutralize the biological activity of CXCL12 of the HA-CMs, $0.5 \mu \mathrm{g} / \mathrm{ml}$ of the goat anti-human CXCL12/SDF-1 neutralizing antibody (R\&D Systems, Inc., ref. AF-310-NA) were added according to the guideline provided by the manufacturer. After $24 \mathrm{~h}$ of incubation at $37^{\circ} \mathrm{C}$, invasive cells were stained with crystal violet and observed using a microscope Motic AE31 and images were acquired with a digital camera (Moticam 5.0 MP). When cells invaded in groups, reliable cell counts were not possible, in those cases crystal violet staining intensity was quantified using the Image Pro Plus software, and the IOD of invading cells was reported.

Analysis of TGF- $\beta$ and cytokine profile. The level of TGF- $\beta$ in the BrC CMs was analyzed with the human TGF- $\beta$ Quantikine ELISA kit (R\&D Systems, ref. DY240) according to the protocol provided by the manufacturer. To determine the cytokine profile of $\mathrm{CMs}$ and sera from patients with $\mathrm{BrC}$, the concentration (in pgs/ml) of G-CSF, GM-CSF, IL- $1 \beta$, IL-2, IL-4, IL-6, IL-8, IL-10, IL-17, IL-12 p70, Interferon- $\alpha 2$ (INF- $\alpha 2$ ), MCP-1, RANTES, EGF, VEGF, CXCL12 (also known as SDF-1), and metalloproteinases MMP-1, MMP-2, MMP-7, MMP-9, and MMP-10 were determined with the MILLIPLEX HCYTOMAG-60K kit (EMD Millipore Corp.) following the manufacturer's recommended procedure. The analysis of data was performed in the XPONENT ${ }^{\circledR}$ Software.

Tumorsphere forming assay. After induction of the invasive/ stemness phenotype, single-cell suspensions were plated in 96-well ultra-low attachment plates (Costar; Corning Inc.) at 100 cells in $100 \mu \mathrm{l}$ of MammoCult medium plus growth factors (Stem Cell Technologies, ref. 05621). Cultures were grown for 7 days. Tumorspheres were observed and photographed using Motic AE31 microscope with a digital camera (Moticam 5.0 MP). Spheres $>50 \mu \mathrm{m}$ were counted and graphed.

Statistical analysis. The Prism software version 5.01 (GraphPad) was used for statistical analysis. A one-way analysis of variance (ANOVA) test with the Tukey as post hoc test was applied to more than two groups of data, and the non-parametric Kruskal-Wallis test with Dunnett's as post hoc test was applied to more than two groups in which the data lack normality and/or homogeneity of variance. Significant P-values are indicated as follows: $\leq 0.05$ by one asterisk *, $\leq 0.01$ by two asterisks ${ }^{* *}$ and $\leq 0.001$ by three asterisks ${ }^{* * *}$.

\section{Results}

Aggressive breast cancer cells promote loss of E-cadherin and invasive features in non-aggressive cells. We defined MCF-7 and T47D ER-positive cells as NA-BrC cells and HS578T and MDA-MB-231 triple-negative cells as HA-BrC cells based on expression of the EMT markers E-cadherin and vimentin and their invasive properties (Fig. 1A and B). In agreement, the former cell lines are non-metastatic in mouse, while the latter are highly metastatic in similar experimental conditions (19). Since during metastasis cellular communication is importantly mediated by secreted factors (20), we assessed whether NA-BrC cells cultured with conditioned media (CM) of HA-BrC cells, and vice-versa, modify each others aggressive characteristics. Fig. 1C shows that MCF-7 cells cultured with the HS578T CM reduced E-cadherin levels from a basal IOD of 22,000 to an IOD of 8,000 , while with the CM of MDA-MB-231 cells E-cadherin levels were undetectable. This reduction of E-cadherin levels correlated well with an acquired capacity of cells to invade, observing an average of 10 and $30 \mathrm{MCF}-7$ invading cells/field when cultured in HS578T and MDA-MB-231 CMs, respectively. The same was true for T47D cells, finding a reduction of the E-cadherin IOD from 50,000 to $<500$, and $15-20$ invading cells/field after culture 
with CM from aggressive cells (Fig. 1D). On the contrary, no significant changes were observed in $\mathrm{HA}-\mathrm{BrC}$ cells cultured with CM derived from NA-BrC cells (data no shown). Thus, these results support the capacity of aggressive tumor cells to laterally transmit aggressive features into non-aggressive cells, characterized by a partial EMT phenotype with reduction of E-cadherin but not significant induction of vimentin, and increased invasiveness.

CXCL12-CXCR4/CXCR7 axis in the inducible-invasive phenotype. CXCL12 is an essential chemokine often involved in the migration of BrC cells (21); similarly CXCL12 receptors CXCR4 and CXCR7, but also CXCR3 and CCR7 mediate metastasis of $\mathrm{BrC}$ cells (22). To further explore the mechanism by which HA-BrC cells induce the migration of NA-BrC cells, we analyzed the concentration of CXCL12 in the CM of the $\mathrm{BrC}$ cells and the expression levels of the chemokine receptors on the NA-BrC cells treated with the $\mathrm{CM}$ of $\mathrm{HA}-\mathrm{BrC}$ cells. Although high levels of CXCL12 were found in the CM of the $\mathrm{BrC}$ cell lines, no significant differences were found between aggressive and non-aggressive cells (Fig. 2A). Of the chemokine receptors, we found a discrete and more heterogeneous result with $\mathrm{CXCR} 3$, contrary to $\mathrm{CXCR} 4, \mathrm{CXCR} 7$ and CCR7 that significantly increased expression solely in response to HA-BrC CMs; CXCR4 and CXCR7 changed in both NA-BrC cells, while CCR7 only on induced T47D cells (Fig. 2B). Since CXCR4 and CXCR7 are CXCL12 receptors, CXCL12 was tested as chemoattractant in invasion assays.

We found that both induced invasive NA-BrC cells migrated in response to this chemokine (Fig. 2C). To address whether the $\mathrm{CM}$ of aggressive cells could also attract cells, NA-BrC cells were cultured with the HA-BrC CMs as before, and then subjected to an invasive assay in which the same $\mathrm{CM}$ used to stimulate them was placed as chemoattractant in the lower chamber of the transwell cameras. We observed that the induced invasive MCF-7 and T47D cells were also migrating in response to the $\mathrm{HA}-\mathrm{BrC} \mathrm{CMs,} \mathrm{with} \mathrm{MCF}-7$ cells seeming more responsive than T47D cells. In addition, the CM of MDA-MB-231 cells gave a more potent response than the CM of HS578T cells, with an average IOD/field of 900,000 for MCF-7 and 320,000 for T47D invading cells (Fig. 2D). Cells did not invade in the absence of CXCL12 (data not shown). To confirm that CXCL12 had a role in the invasive phenotype, invasion assays were performed on the induced invasive MCF-7 and T47D cells using the $\mathrm{CM}$ of the $\mathrm{BrC}$ cell lines, either alone or plus a CXCL12 neutralizing antibody. We observed that the stimulated NA-BrC cells decreased their invasiveness in the presence of the inhibitory antibody (Fig. 2E). These data support that the $\mathrm{CM}$ of $\mathrm{HA}-\mathrm{BrC}$ cells induce migratory properties on NA-BrC cells together with upregulation of CXCR4 and CXCR7 expression, and that these induced invasive NA-BrC cells then move in response to CXCL12.

A TGF- $\beta$ independent but G-CSF, GM-CSF, IL-8 and $M C P-1$ dependent response. We addressed whether TGF- $\beta$ was responsible for the inducible-invasive phenotype. When we quantified TGF- $\beta$ levels in the $\mathrm{CM}$ of the $\mathrm{BrC}$ cell lines, we found a higher concentration of this cytokine in the $\mathrm{CM}$ of the HA-BrC cell lines (average of 343 and $377 \mathrm{pgs} / \mathrm{ml}$ in HS578T and MDA-MB-231 cells, respectively) than in the
NA-BrC CMs (80 and $14 \mathrm{pgs} / \mathrm{ml}$ in T47D and MCF-7 cells, respectively) (Fig. 3A). We then used a TGF- $\beta$ neutralizing antibody to assess whether this cytokine was responsible for the inducible-invasive phenotype of NA-BrC cells. To do this, NA-BrC cells were stimulated for $72 \mathrm{~h}$ with $\mathrm{CM}$ from $\mathrm{HA}-\mathrm{BrC}$ cells in the presence of the TGF- $\beta$ neutralizing antibody. Surprisingly, when expression of E-cadherin was assessed we still observed a significant reduction of the E-cadherin IOD promoted by the HA-BrC CMs (Fig. 3B). Similarly, the stimulated NA-BrC cells remain invasive in spite of the presence of the neutralizing antibody (Fig. 3C). Additionally, we added exogenous TGF- $\beta$ at various concentrations to MCF-7 and T47D cells for $72 \mathrm{~h}$, with no observed variations in E-cadherin or vimentin expression. Accordingly, we did not observe a TGF- $\beta$-induced invasiveness (Fig. 3D). TGF- $\beta$ is known to induce its own expression in Caski cervical cancer cells (23). Exogenous TGF- $\beta$ increased its own gene expression in Caski cells, and the neutralizing antibody abolished this induction, indicating that both recombinant TGF- $\beta$ and the anti-TGF- $\beta$ antibody were functional (data no shown).

We then analyzed for the presence of the following growth factors, cytokines, chemokines and matrix metalloproteinases (MMPs) in the $\mathrm{CM}$ of the $\mathrm{BrC}$ cell lines, which have been previously associated with tumor cell invasion and/ or EMT (24,25): Granulocyte-colony stimulating factor (G-CSF), Granulocyte macrophage-colony stimulating factor (GM-CSF), IL-1 $\beta$, IL-2, IL-4, IL-6, IL-8, IL-10, IL-17, IL-12p70, Interferon- $\alpha 2$ (INF- $\alpha 2$ ), Monocyte chemoattractant protein-1 (MCP-1), Regulated on activation, normal T-cell expressed and secreted (RANTES, also known as CCL5), epidermal growth factor (EGF), Vascular endothelial growth factor (VEGF), MMP-1, MMP-2, MMP-7, MMP-9 and MMP-10. Important differences between the CMs of NA- and $\mathrm{HA}-\mathrm{BrC}$ cells were found in the levels of G-CSF, GM-CSF, IL-8 and MCP-1 (Fig. 4A). These cytokines are known to induce differentiation, proliferation and activation of myeloid cells recruited to the tumor microenvironment, and often, they also induce autocrine activation of tumor cells (26-28). To assess whether these factors participate in the inducibleinvasive phenotype, MCF-7 and T47D cells were cultured in media supplemented with G-CSF, GM-CSF, IL-8 and MCP-1 for $72 \mathrm{~h}$. We found that MCF-7 cells were highly responsive to these cytokines with G-CSF and GM-CSF inducing a partial loss, and IL- 8 and MCP-1 an almost complete loss of E-cadherin levels (Fig. 4B left plot), we also observed that the expression of CXCR4 significantly increased in response to all cytokines while CXCR7 increased only in response to IL-8 and MCP-1 (Fig. 4C left plots), which closely correlated with induction of invasiveness (Fig. 4D left panels). Overall, these data show a great correlation between IL-8/MCP-1-induction of CXCR7 and E-cadherin reduction/increased invasion.

Somehow the results obtained with T47D cells were more complex. We only observed a very discreet but significant reduction of E-cadherin levels on T47D cells, and specifically upon stimulation with IL-8 and MCP-1 (Fig. 4B right plot). We also observed an increase of CXCR4 expression in response to all cytokines, while CXCR7 increased expression only in response to IL-8 and MCP-1 (Fig. 4C right plots). However, the T47D invasion assay was not as clear, since G-CSF, GM-CSF and MCP-1 were able to induce invasion but IL- 8 was 

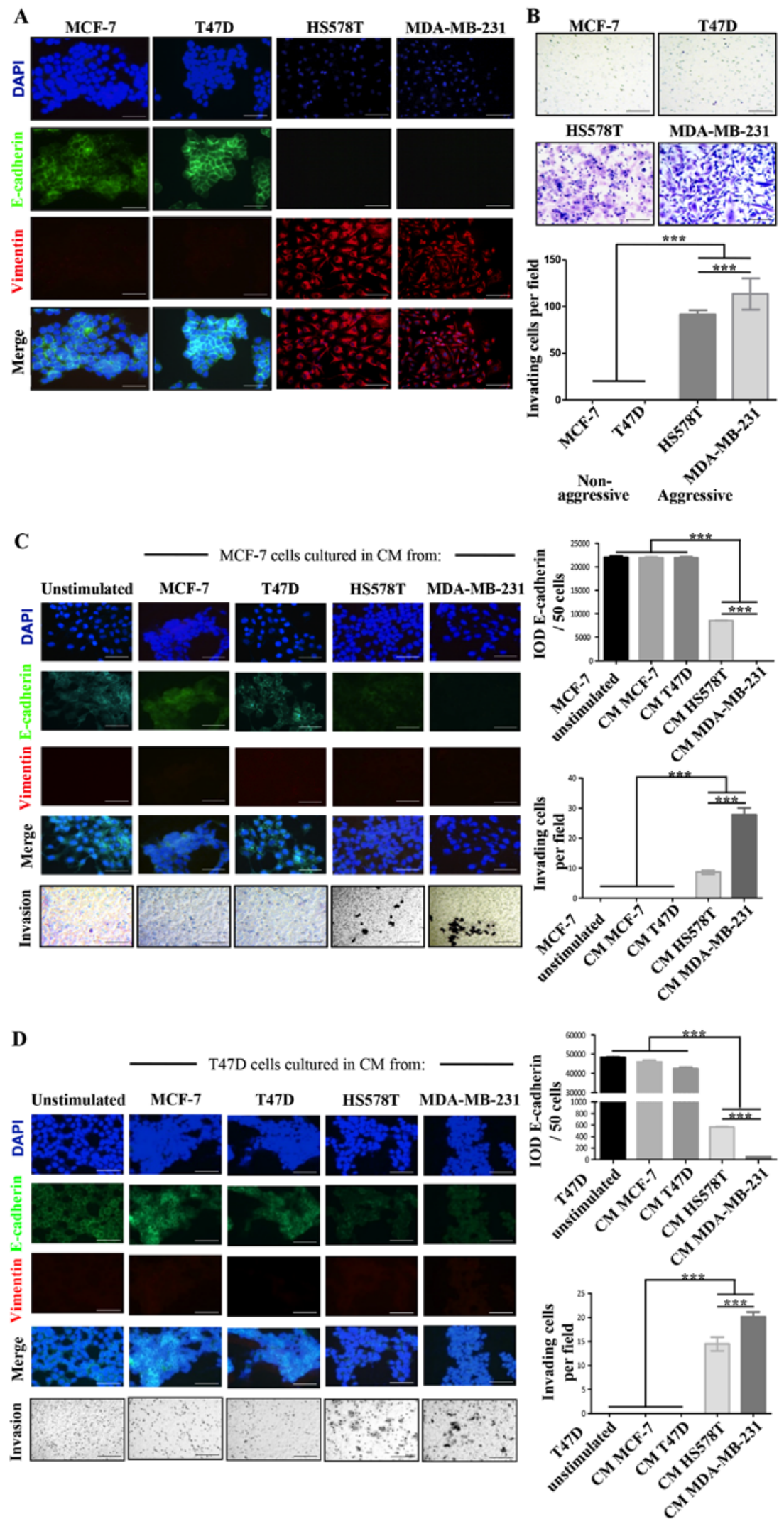

Figure 1. Aggressive breast cancer cells promote mesenchymal and invasive features in non-aggressive cells. (A) Analysis of the basal expression levels of epithelial to mesenchymal (EMT) markers E-cadherin (green) and vimentin (red), nuclei (DAPI, blue) by immunofluorescence (IF) staining. (B) Invasion assays. (C) MCF-7 cells were cultured with CM from HA-BrC cell lines HS578T and MDA-MB-231 for $72 \mathrm{~h}$. As controls, MCF-7 cells were cultured with NA-BrC CMs or were cultured in their regular media (unstimulated). Left panels show representative IF images of EMT markers and optical images of invasion assays. Right panels show plots of the integrated optical density (IOD) of E-cadherin levels and the number of invasive cells. Aggressive breast cancer cells promote mesenchymal and invasive features in non-aggressive cells. (D) T47D cells were cultured with CM from HA-BrC cell lines HS578T and MDA-MB-231 for $72 \mathrm{~h}$. As controls, T47D cells were cultured with NA-BrC CMs or were cultured in their regular media (unstimulated). Left panels show representative IF images of EMT markers and optical images of invasion assays. Right panels show plots of the integrated optical density (IOD) of E-cadherin levels and the number of invasive cells. Representative images are shown. Data represent the mean \pm SEM (standard error of the mean) from 3 independent experiments; ${ }^{* * * *} \mathrm{P}<0.001$. Scale bars indicate $100 \mu \mathrm{m}$. Magnification of $\mathrm{x} 400$ for IF images and $\mathrm{x} 100$ for optical images. 
$\mathbf{A}$

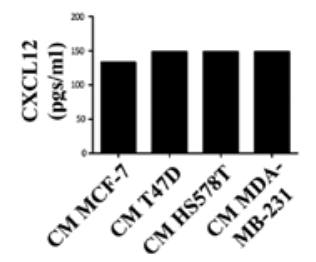

B
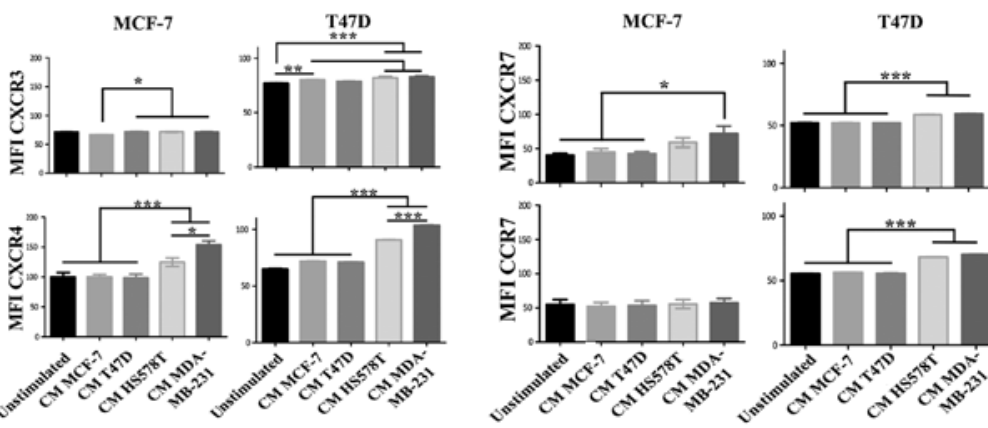

C
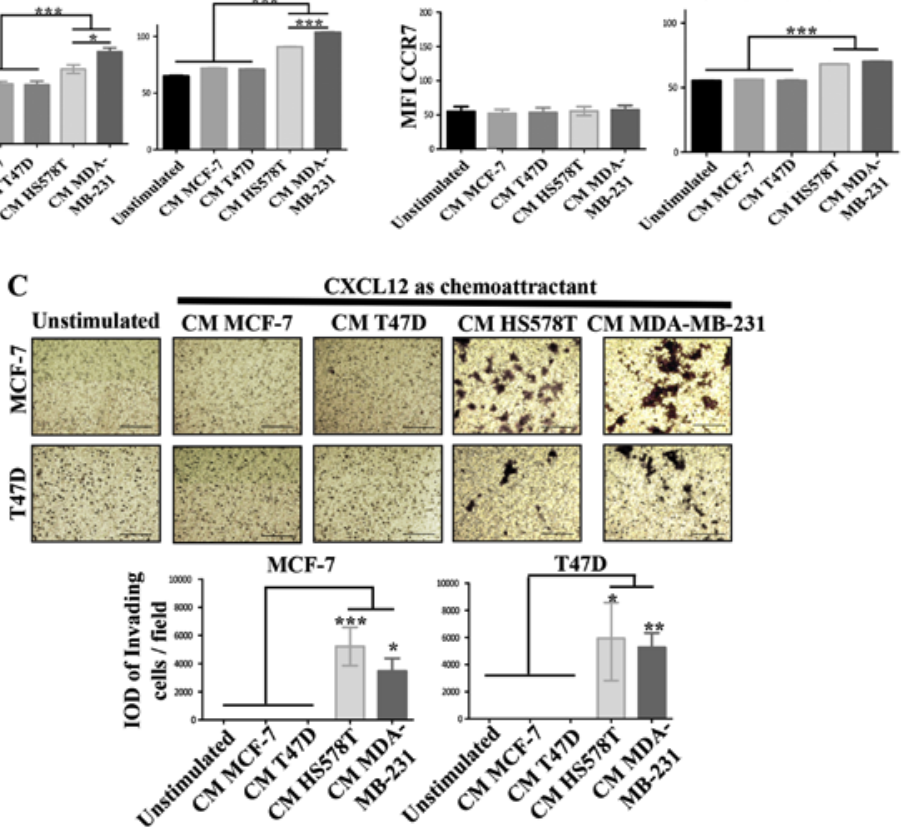

D
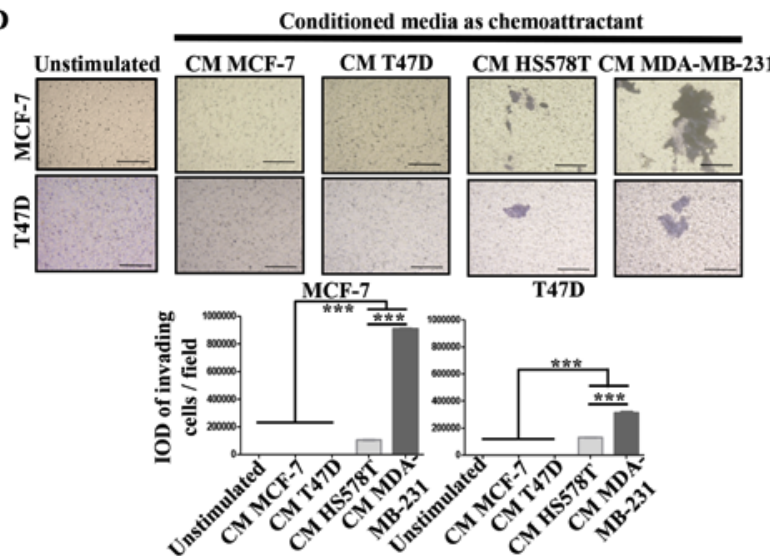

$\mathbf{E}$

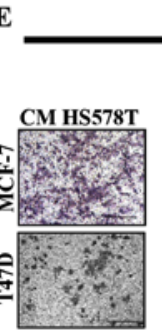

Conditioned media as chemoattractant CM HS578T CM MDA-MB-231

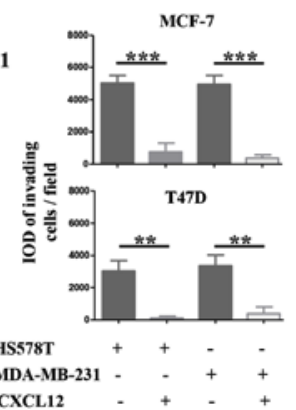

Figure 2. The CXCL12-CXCR4/CXCR7 axis in the inducible-invasive phenotype. (A) Levels of CXCL12 expressed in pgs/ml in the CMs of the BrC cell lines. (B) MCF-7 and T47D cells were cultured with CM from HA-BrC cell lines and controls, and expression of chemokine receptors was analyzed by flow cytometry. (C) CXCL12 or (D) CMs as chemoattractants. (E) CMs from the HA BrC cells were used as chemoattractants and $0.5 \mu \mathrm{g} / \mathrm{ml}$ of an anti-CXCL12 neutralizing antibody was added to the CMs. Invasive cells were quantified after $24 \mathrm{~h}$ (magnification of $\mathrm{x} 100$ ). The integrated optical density (IOD) values of invading cells were plotted. Data represent the mean \pm SEM from 3 independent experiments.; ${ }^{*} \mathrm{P}<0.05,{ }^{* *} \mathrm{P}<0.01$ and ${ }^{* * *} \mathrm{P}<0.001$. Scale bars indicate $100 \mu \mathrm{m}$. 
Table I. Clinical characteristics of the patients.

\begin{tabular}{|c|c|c|c|c|}
\hline $\begin{array}{l}\text { Serum from } \\
\text { patients }\end{array}$ & $\begin{array}{l}\text { Histological } \\
\text { subtype }\end{array}$ & $\begin{array}{c}\text { TNM } \\
\text { staging }\end{array}$ & $\begin{array}{l}\text { Clinical } \\
\text { stage }\end{array}$ & $\begin{array}{c}\text { Molecular } \\
\text { classification }\end{array}$ \\
\hline UIVC-IDC-13 & IDC & $\mathrm{T} 2, \mathrm{~N} 0, \mathrm{M} 0$ & IIA & Triple-negative \\
\hline UIVC-IDC-14 & IDC & $\mathrm{T} 1, \mathrm{~N} 0, \mathrm{M} 0$ & I & Luminal B \\
\hline UIVC-IDC-15 & IDC & T1, N0, M0 & I & Luminal A \\
\hline UIVC-IDC-16 & IDC & $\mathrm{T} 1, \mathrm{~N} 0, \mathrm{M} 0$ & I & Triple-negative \\
\hline UIVC-IDC-17 & IDC & WD & WD & Her-2 \\
\hline UIVC-IDC-18 & IDC & WD & WD & Luminal A \\
\hline UIVC-IDC-19 & IDC & $\mathrm{T} 2, \mathrm{~N} 0, \mathrm{M} 0$ & IIA & Triple-negative \\
\hline UIVC-IDC-20 & IDC & WD & WD & Luminal B \\
\hline UIVC-IDC-21 & IDC & WD & WD & Her-2 \\
\hline UIVC-IDC-22 & IDC & T1, N0, M0 & I & Luminal A \\
\hline UIVC-IDC-23 & IDC & $\mathrm{T} 1, \mathrm{~N} 1, \mathrm{M} 0$ & IIA & Luminal A \\
\hline UIVC-IDC-24 & IDC & T1, N0, M0 & I & Luminal A \\
\hline UIVC-IDC-25 & IDC & T2, N0, M0 & IIA & Triple-negative \\
\hline UIVC-IDC-26 & IDC & $\mathrm{T} 2, \mathrm{~N} 0, \mathrm{M} 0$ & IIA & Her-2 \\
\hline UIVC-IDC-27 & IDC & T2, N0, M0 & IIA & Luminal A \\
\hline UIVC-IDC-28 & IDC & $\mathrm{T} 2, \mathrm{~N} 1, \mathrm{M} 0$ & IIB & Her-2 \\
\hline UIVC-IDC-29 & IDC & T1, N0, M0 & $\mathrm{I}$ & Luminal A \\
\hline UIVC-IDC-30 & IDC & T3, N0, M0 & IIB & Luminal A \\
\hline UIVC-IDC-31 & IDC & T2, N0, M0 & IIA & Luminal A \\
\hline UIVC-IDC-32 & IDC & $\mathrm{T} 1, \mathrm{~N} 0, \mathrm{M} 0$ & I & Her-2 \\
\hline UIVC-IDC-33 & IDC & T3, N1, M0 & IIIA & Luminal A \\
\hline UIVC-IDC-34 & IDC & $\mathrm{T} 2, \mathrm{~N} 0, \mathrm{M} 0$ & IIA & Luminal B \\
\hline UIVC-LC-2 & ILC & T3, N1, M0 & IIIA & Triple-negative \\
\hline UIVC-LC-3 & ILC & $\mathrm{T} 2, \mathrm{~N} 1, \mathrm{M} 0$ & IIB & Luminal A \\
\hline UIVC-MC-2 & $\mathrm{MC}$ & $\mathrm{T} 1, \mathrm{~N} 1, \mathrm{M} 0$ & IIA & Luminal B \\
\hline UIVC-MC-3 & $\mathrm{MC}$ & T3, N1, M0 & IIIA & Luminal B \\
\hline UIVC-MC-4 & $\mathrm{MC}$ & $\mathrm{T} 2, \mathrm{~N} 0, \mathrm{M} 0$ & IIA & Her-2 \\
\hline UIVC-MC-5 & $\mathrm{MC}$ & $\mathrm{T} 2, \mathrm{~N} 0, \mathrm{M} 0$ & IIA & Luminal A \\
\hline
\end{tabular}

IDC, invasive ductal carcinoma; ILC, invasive lobular carcinoma; MC, mixed (lobular/ductal) carcinoma; WD, without data.

not (Fig. 4D right panels). Of note, FBS was a more powerful chemoattractant of cytokine-activated T47D cells (Fig. 4E), while CXCL12 was for MCF-7 cells (Fig. 4D), even in cells stimulated with IL-8. A cocktail with all four cytokines did not further promote E-cadherin loss or increased invasion of NA-BrC cells (data not shown). Vimentin expression was not induced in these experimental conditions as we have previously observed with the HA-BrC CMs (data not shown and Fig. 1C and D). Overall these data support an important role for GM-CSF, G-CSF, IL-8 and MCP-1 on the inducibleinvasive phenotype of NA-BrC cells, with an IL-8 and MCP-1 stronger activity on MCF-7 cells and a more variegated effect on T47D cells. Of note, these data point out that even though MCF-7 and T47D cells are highly plastic reacting to signals communicated by aggressive tumor cells, there are significant differences between the mechanisms of induced-aggressive behavior displayed by each cell line. We tested the concentration of CXCL12, G-CSF, GM-CSF, IL-8 and MCP-1 cytokines and of MMP-1 and MMP-2 metalloproteinases in sera of BrC patients (see Table I for the clinical characteristics of patients) and healthy controls, finding detectable levels of all analytes tested. Since we could only obtain five sera of each $\mathrm{BrC}$ subtype no statistical analysis was performed (Fig. 4F).

CD44, Oct4 and Sox2 are upregulated in induced-invasive cells. The hyaluronan receptor (also known as CD44) has been widely associated with a CSC-like phenotype, and Oct-4 and Sox-2 are essential transcription factors involved in maintenance of pluripotency during embryogenesis, and their induced-expression has been evidenced in several types of cancer upon acquisition of metastatic potential and EMT $(29,30)$. When we evaluated the expression of these CSC markers on the $\mathrm{BrC}$ cell lines we found that $\mathrm{CD} 44$ positive cells were not (MCF-7 $=0 \%$ of positive cells) or rarely represented (T47D $=2.83 \%$ ) on NA-BrC cells, while they were highly represented on HS578T (90.8\%) and MDA-MB-231 (96.1\%) HA-BrC cells (Fig. 5A). A similar observation was made for Oct-4 and Sox-2 (Fig. 5B). We addressed whether the inducible-invasive trait correlated with acquisition of these stem markers. We found that both the frequency of CD44 positive cells and the MFI of CD44 expression were induced upon treatment with the HA-BrC CMs in both MCF-7 and T47D NA-BrC cells (Fig. 5C and D, respectively). T47D cells were the most sensitive cells to stimulation as more than half of the cells expressed CD44 upon treatment with the MDA-MB-231 $\mathrm{CM}$. We also observed a significantly increased expression of Oct-4 and Sox-2 in MCF-7 cells upon stimulation with the CM from HA-BrC cell lines (Fig. 5E). T47D cells significantly changed the expression of Sox-2 upon stimulation, while the levels of Oct-4 remained low (Fig. 5F).

A more quantitative analysis of the frequency of Sox-2 expressing cells by flow cytometry confirmed the results obtained with the immunofluorescence analyses (Fig. 5G). Since the formation of tumorspheres is a model of CSC seeding and expansion (31), we addressed the $\mathrm{BrC}$ cell lines basal and induced potential of formation of tumorspheres. We observed that all the cell lines exhibited similar capacities of formation of tumorospheres (Fig. 5H), the only difference found was the morphology of the spheres, with $\mathrm{HA}-\mathrm{BrC}$ cells forming less adherent spheres that resemble cell aggregates, typical of aggressive cell lines with low expression of adhesion proteins (32). When NA-BrC cells were treated with the CM of $\mathrm{HA}-\mathrm{BrC}$ cells, the frequency and morphology of the tumorspheres remained unchanged; however, spheres of increased size were observed (Fig. 5I). Taken together all these data show that the inducible-invasive trait correlates with acquisition of a CSC-like phenotype defined by expression of CD44, Oct-4 and Sox-2 stemness markers, and also with the formation of larger tumorspheres in low adherent plates.

\section{Discussion}

The original conception of cancer initiation and progression highlighted the importance of accumulation of genetic mutations, with tumors exhibiting greater genetic heterogeneity also exhibiting an increased risk to display more aggressive features. More recent studies have also highlighted the capacity of the tumor to communicate with non-tumor cells within the tumor 
$\mathbf{A}$

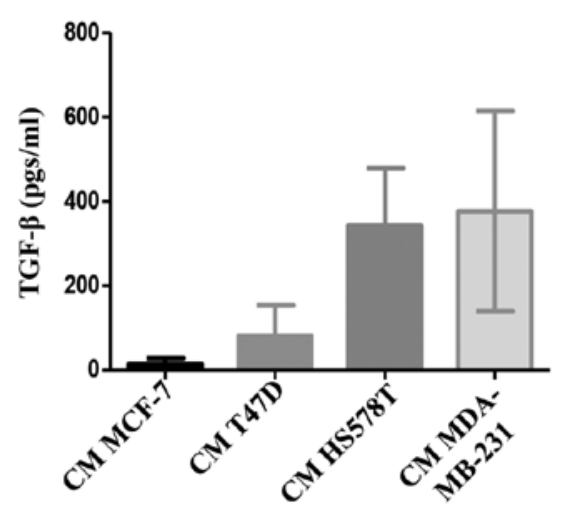

B

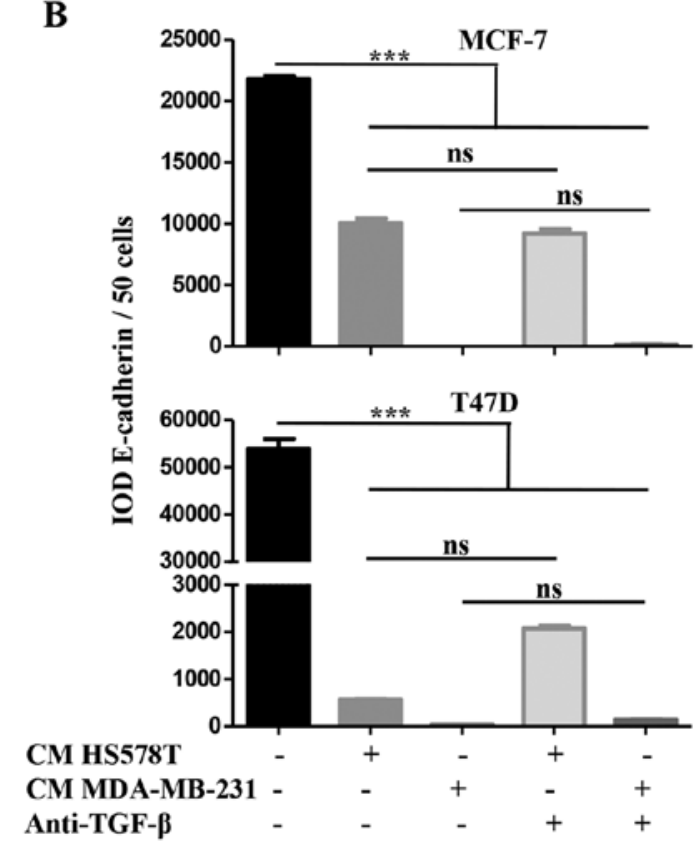

CM MDA-MB-231

Anti-TGF- $\beta$

C

C CM-MDA-
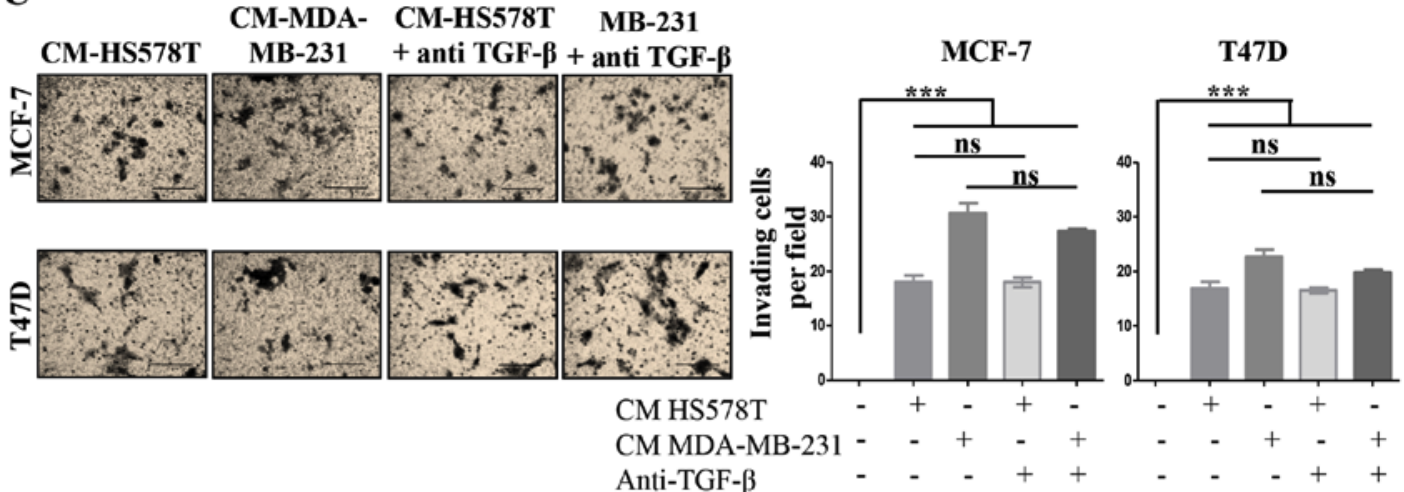

CM MDA-M

D
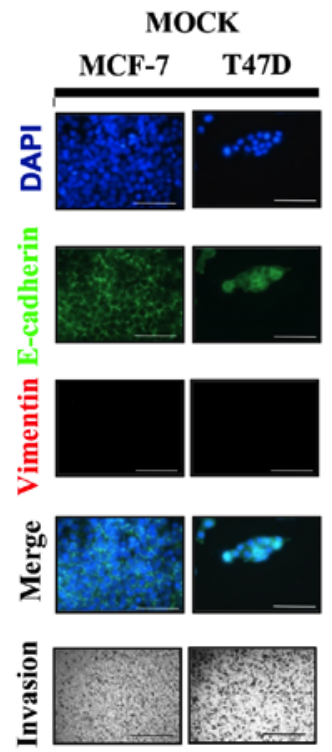
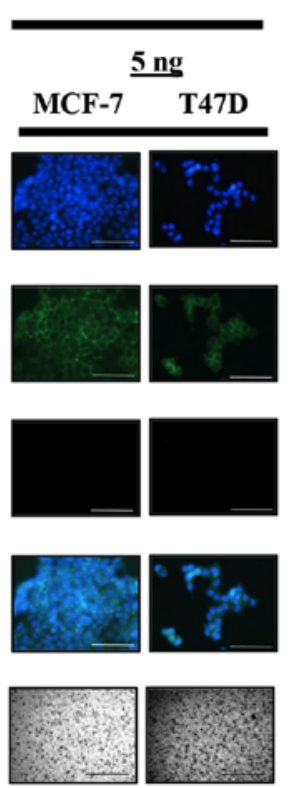

TGF- $\beta$

$10 \mathrm{ng}$
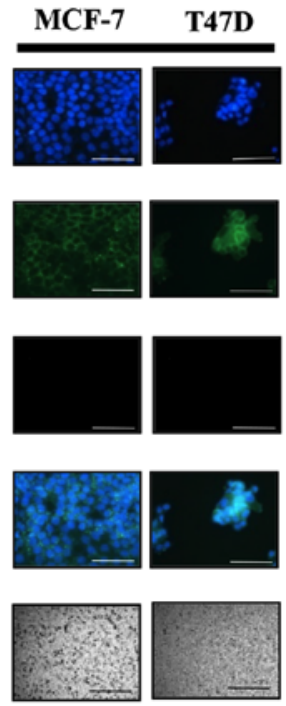
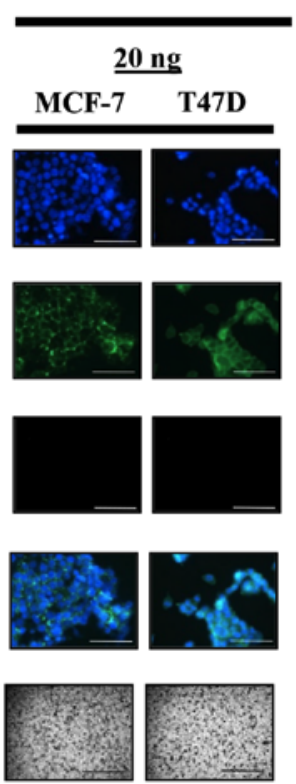

Figure 3. The inducible-invasive phenotype is TGF- $\beta$ independent. (A) The concentration expressed in pgs/ml of TGF- $\beta$ was measured in the CM from all $\mathrm{BrC}$ cell lines and data were plotted. The inducible-invasive phenotype of MCF-7 and T47D cells was activated with $\mathrm{HA}-\mathrm{BrC} \mathrm{CMs}$ in the presence of $2 \mu \mathrm{g} / \mathrm{ml}$ of neutralizing anti-TGF- $\beta$. After $72 \mathrm{~h}$ of culture, (B) EMT markers were analyzed by IF and IODs of E-cadherin expression were quantified and plotted. (C) Invasion assays were performed. Left panels show representative images of invading cells and right plots show the number of invading cells. (D) Analysis of EMT markers and invasion assays of NA-BrC cell lines treated with increasing concentrations of TGF- $\beta$. Representative images are shown. Data represents the mean \pm SEM from 3 independent experiments; ${ }^{*}{ }^{*} \mathrm{P}<0.001$; ns, non-significant. Scale bars indicate $100 \mu \mathrm{m}$, magnification of $\mathrm{x} 400$ for IF and $\mathrm{x} 100$ for invasion assays. 

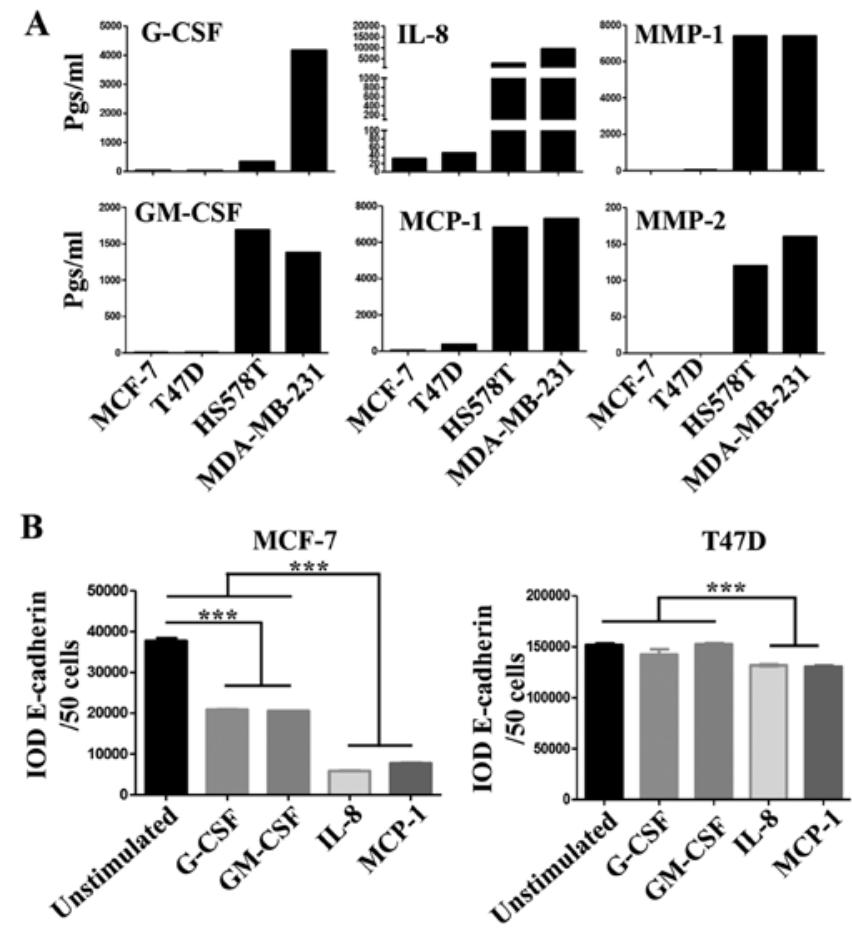

C
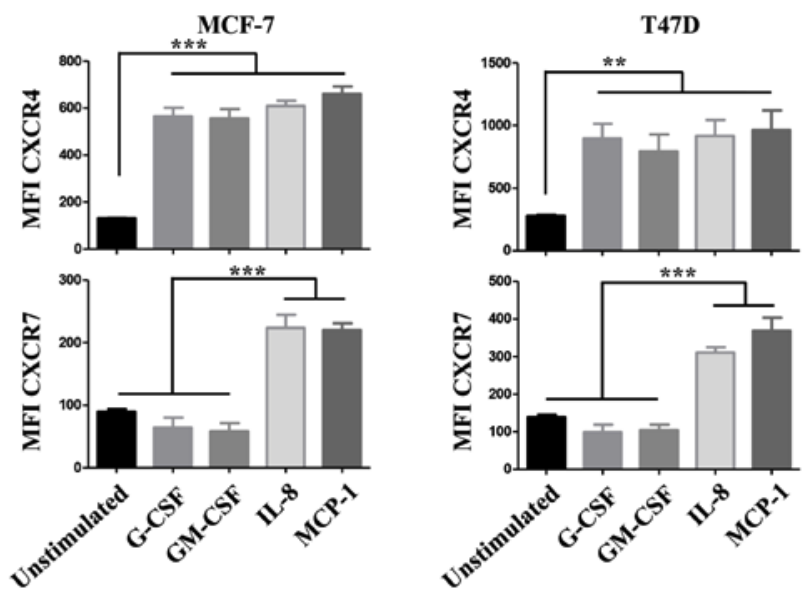

D

CXCL12 as chemoattractant
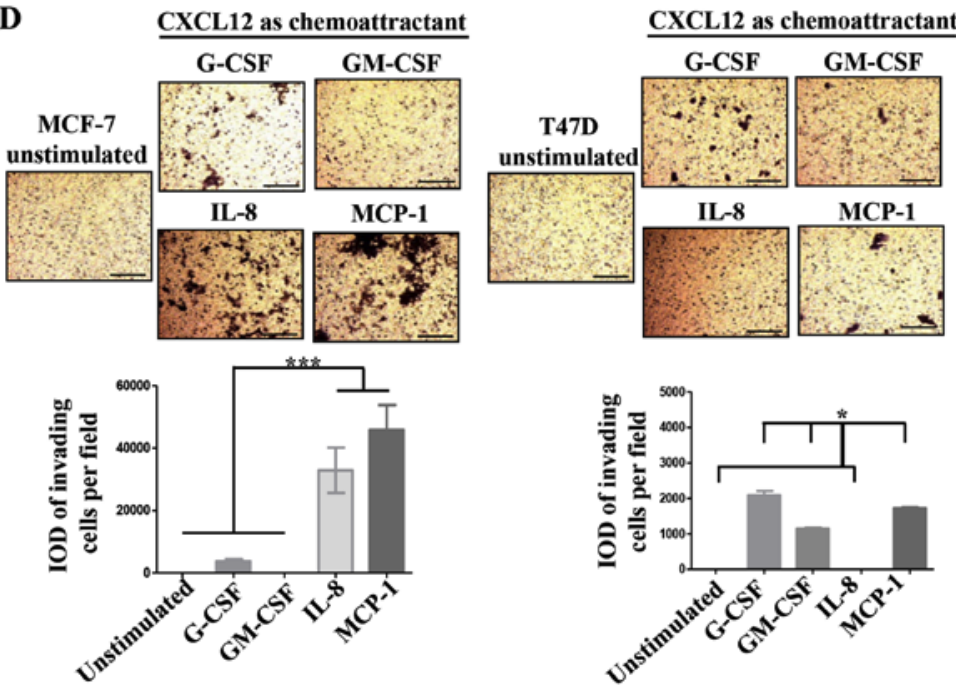

Figure 4. (A-D) The role of pro-inflammatory mediators in the inducible-invasive phenotype. (A) Milliplex assays were performed to determine the concentration of pro-inflammatory mediators and metalloproteinases (expressed in $\mathrm{pgs} / \mathrm{ml}$ ) in all the CMs; only analytes exhibiting significant differences between the CMs of NA- and HA-BrC cells are shown. MCF-7 and T47D cells were cultured with $100 \mathrm{ng} / \mathrm{ml}$ of any of the following: G-CSF, GM-CSF, IL-8 or MCP-1 for $72 \mathrm{~h}$. (B) Analysis of the EMT marker E-cadherin by IF. (C) Plots of the analysis of CXCR4 and CXCR7 chemokine receptor expression by flow cytometry. Invasion assays using CXCL12 (D) as chemoattractant. Representative images and plots of resulting data are shown. Data represent the mean \pm SEM from 3 independent experiments; ${ }^{*} \mathrm{P}<0.05,{ }^{* *} \mathrm{P}<0.01$ and ${ }^{* * *} \mathrm{P}<0.001$. In the panels of T47D cells of (D), IL-8 was significantly different than the other cytokines $($ ( $\mathrm{P}<0.05)$. Scale bars indicate $100 \mu \mathrm{m}$ and magnification, $\mathrm{x} 100$. 
E

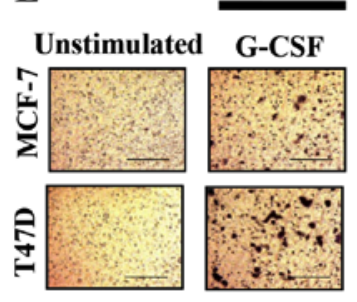

MCF-7

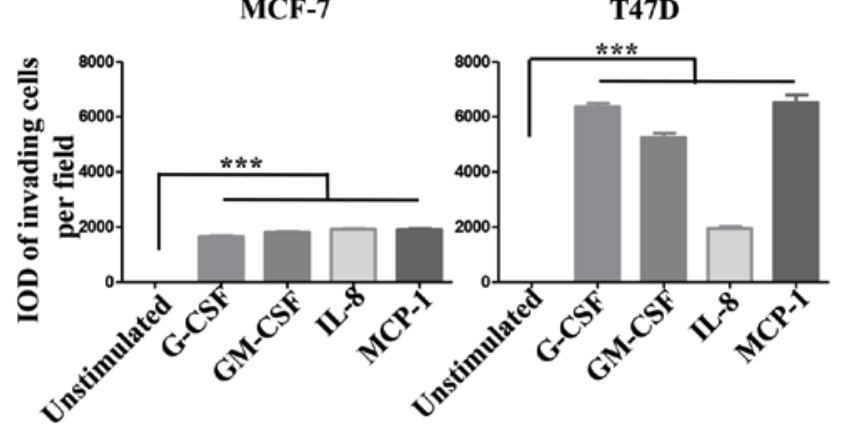

FBS as chemoattractant
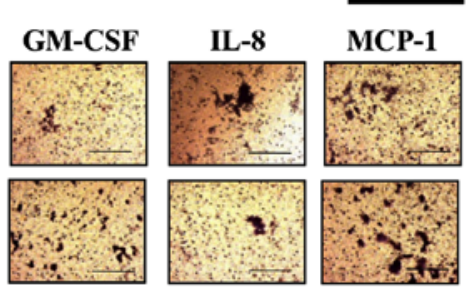

T47D
F
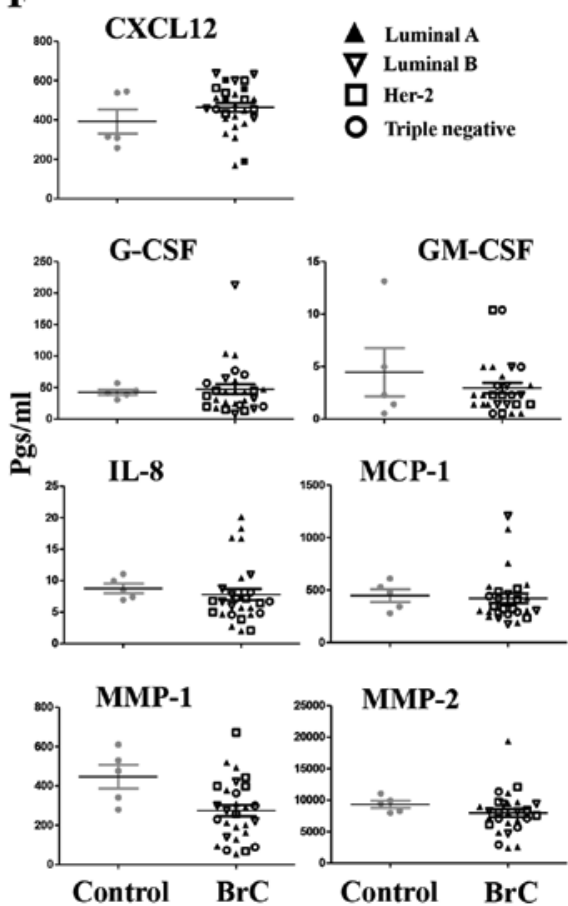

Figure 4. Continued. (E and F) The role of pro-inflammatory mediators in the inducible-invasive phenotype. Invasion assays using fetal bovine serum (FBS) (E) as chemoattractant. (F) A Milliplex assay was performed to determine the sera concentration of the pro-inflammatory mediators and metalloproteinases of interest in BrC patients and controls. Representative images and plots of resulting data are shown. Data represent the mean \pm SEM from 2 independent experiments; ${ }^{* * *} \mathrm{P}<0.001$. Only two duplicates were analyzed $(\mathrm{F})$. Scale bars indicate $100 \mu \mathrm{m}$ and magnification, $\mathrm{x} 100$.

microenvironment as the source of aggression (5). In this study, we evidenced a potential mechanism of paracrine communication between tumor cells that results in lateral transmission of aggressive features. The induced aggressive characteristics consist of acquisition of a partial EMT phenotype with loss of E-cadherin but without gain of vimentin expression, gain of CSC markers CD44, Sox-2 and Oct-4, increased expression of CXCL12 receptors CXCR4 and CXCR7, and increased invasiveness in response to CXCL12. Altogether, these mechanisms of tumor communication may facilitate the appearance of new clones with novel functions, further extending the clonal heterogeneity that increases the tumor aggressive potential without relying on genetic irreversible mutations.

The clonal evolution model of tumors points out that distinct genetic clones exhibit differential fitness, and only those clones with specific advantages and under particular selective pressures will be maintained, favoring the progression of disease in a kind of Darwinian evolution competition (33). In 2014, Marusyk et al proposed that interactions between rare and affluent tumor clones favored the emergence of clones with novel phenotypes and functions allowing the tumor to adapt to microenvironmental changes (34). Other studies support intra-clonal communication and cooperation, particularly among metastatic and non-metastatic clones $(6,7,11)$, adding another layer of complexity to the origin and evolution of tumors. The plasticity of the tumor cell has been extensively studied, with the EMT at the center of this plasticity. More recent evidence support that cancer cells undergoing EMT also increase expression of stem markers, and tumors in which the EMT/stemness programs are active, are also more invasive and metastatic denoting cancers with the worst clinical outcomes $(16,17,24,35,36)$. How the EMT and stemness programs support tumor heterogeneity and intraclonal coexistence to facilitate tumor maintenance remains as one of the most challenging puzzles in cancer biology. Interestingly, although TGF- $\beta$ is one of the best characterized EMT triggers (15), we could not find any evidence of a TGF- $\beta$ participation in the inducible invasive stem-like phenotype.

To our knowledge, Mani et al in 2008 were the first to describe a strong correlation between EMT and stemness (16), laying the bases for a novel understanding of tumor plasticity and tumor aggression. Today, mounting evidence supports that association; for instance, $\mathrm{BrCs}$ with a high density of CD44- positive cells are specifically associated with reduced disease-free survival (37). Expression of Oct-4 and Sox-2 is also associated with poor clinical outcomes in BrC patients $(38,39)$. While we were working in this study, Mukherjee et al reported that CSCs with different capacities of migration co-exist within primary tumors and in MCF-7 mamospheres. Low migrating inner core CSCs have the capacity to induce migratory properties into outer core nonCSCs through paracrine secretion of EGF, TGF- $\beta 1$, VEGF and IL-6 (11). In agreement with our study, induced non-CSCs showed increased expression of stemness markers CD44, Oct-4 and Sox-2, and invasion was marked by upregulation of CXCR4. We observed an increased expression of CXCR4 and CXCR7 on induced-NA-BrC cell lines, which promoted cell migration in response to CXCL12, particularly in induced MCF-7 cells. In the case of T47D there is not a clear correlation that could be explained because contrary to MCF-7 cells, T47D cells also upregulate CXCR3 and CCR7 expression, as it can be observed in Fig. 2B. Still, the CXCR4/CXCR7/CXCL12 

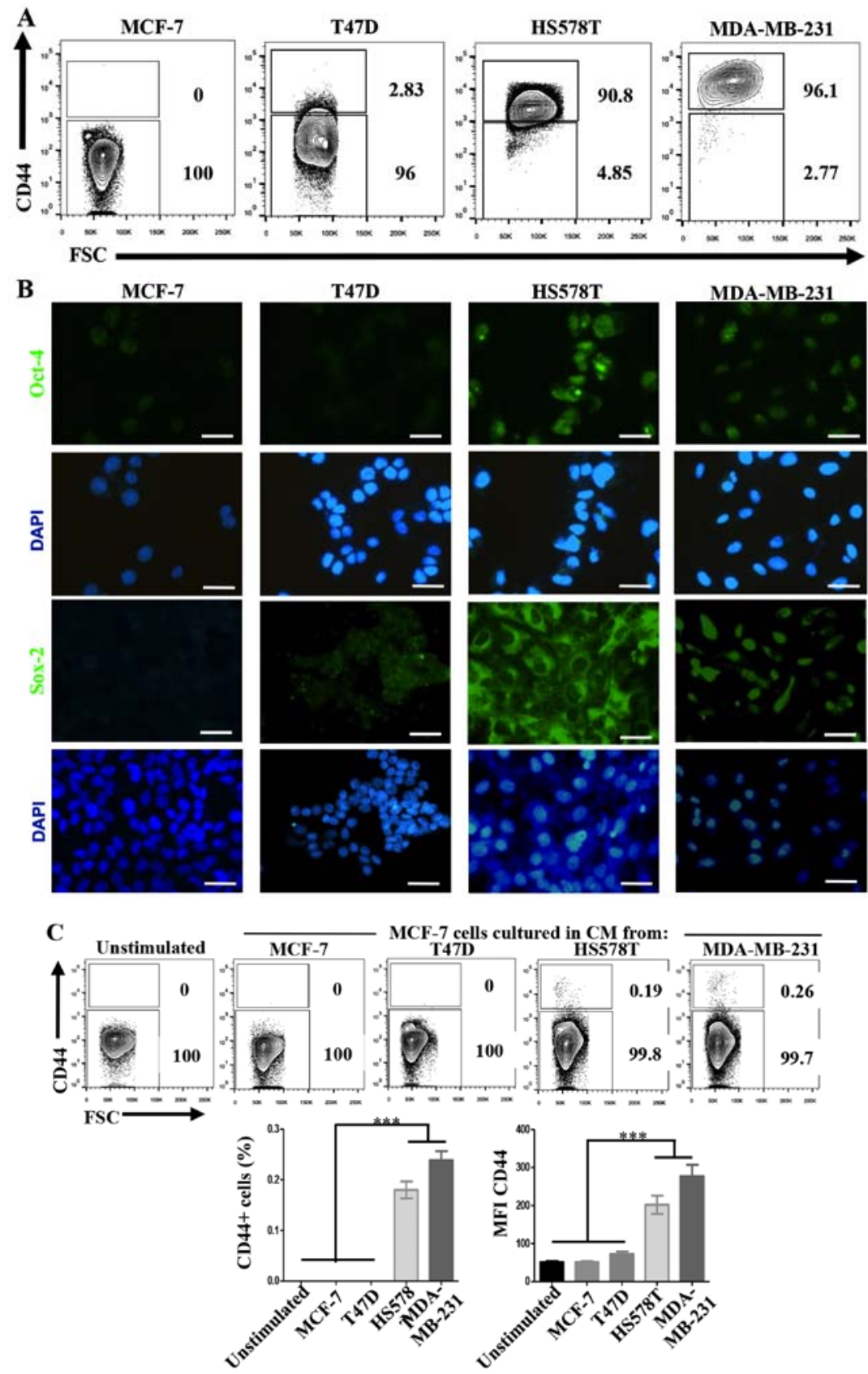

$\mathbf{D}$

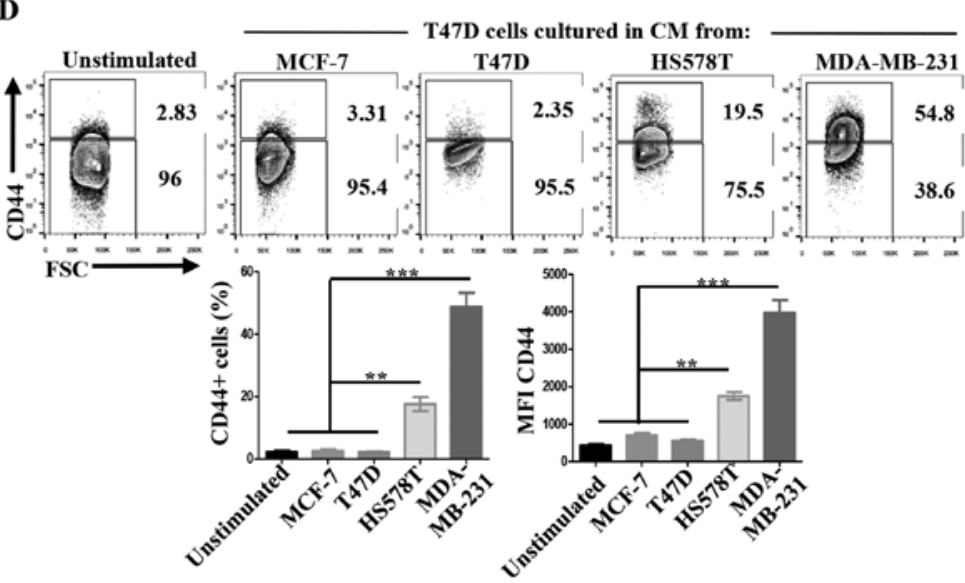

Figure 5. (A-D) The induced-invasive phenotype correlates with acquisition of stemness markers. Analysis of the basal expression levels of stemness markers: CD44 by flow cytometry (A), and of Oct- 4 and Sox-2 by immunofluorescence (IF) (B). Rrepresentative images are shown. Scale bars indicate $100 \mu \mathrm{m}$ (B). Magnification, $x 400$. Analysis of the expression levels of CD44 after induction of the invasive phenotype in MCF-7 (C) and T47D (D) cells. The upper panel shows CD44 expression and the lower panel shows plots of the frequency of CD44+ cells and the CD44 MFI. Data represent the mean \pm SEM from 3 independent experiments, representative images are shown. ${ }^{* *} \mathrm{P}<0.01$ and ${ }^{* * * *} \mathrm{P}<0.001$. 

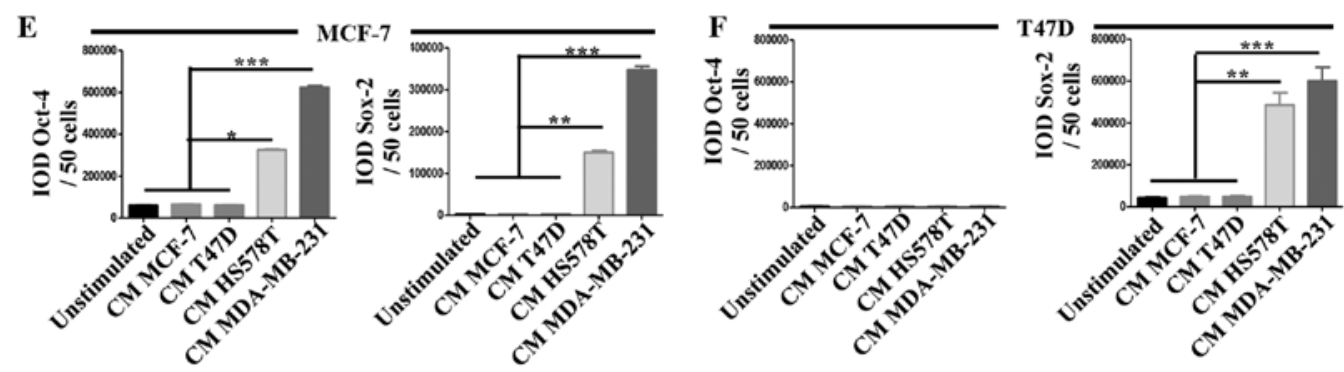

$\circ$
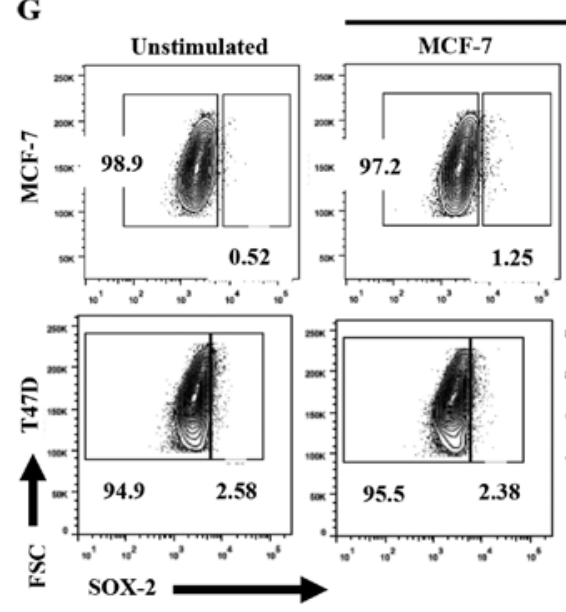

Cells cultured in CM from:
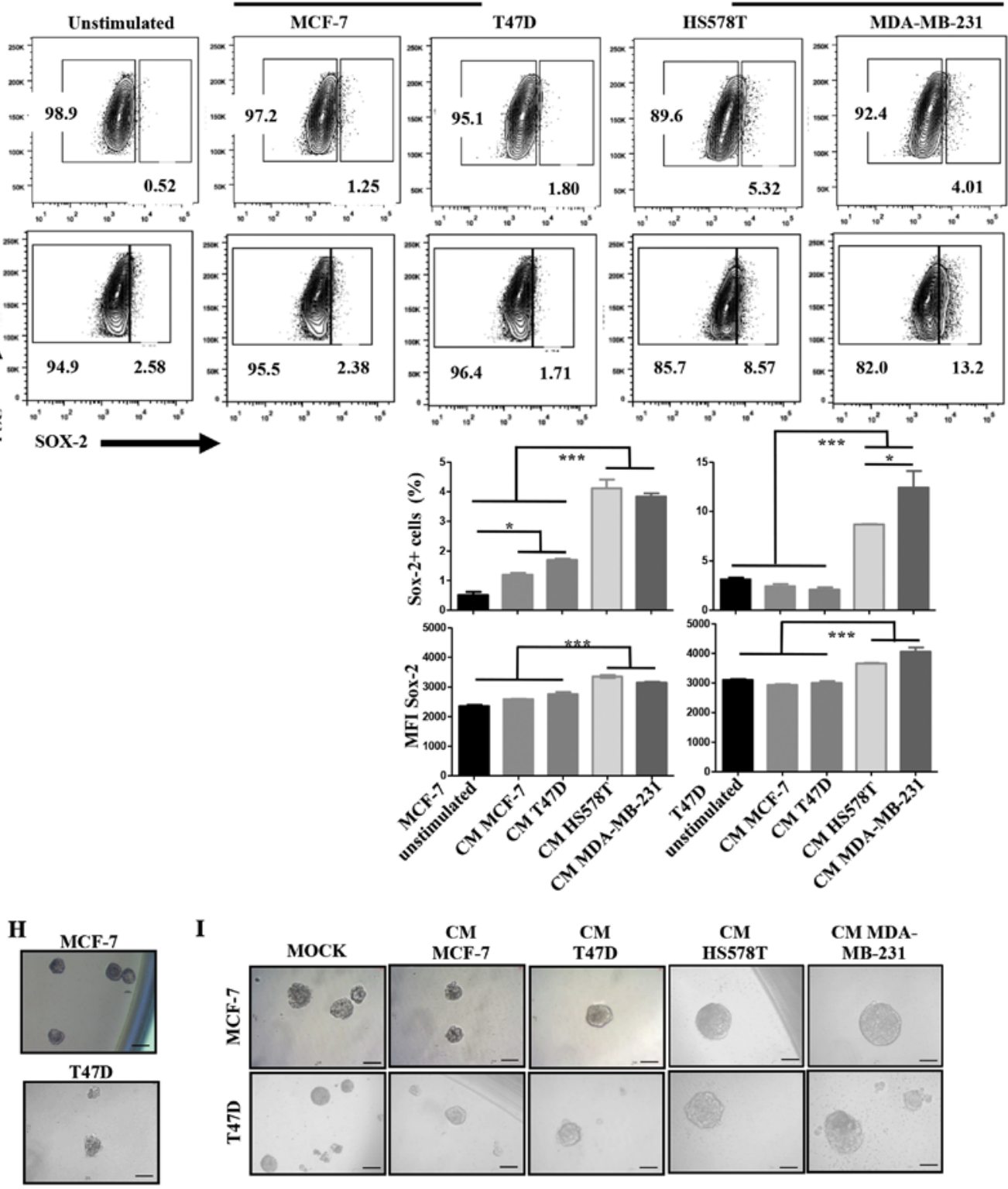

I
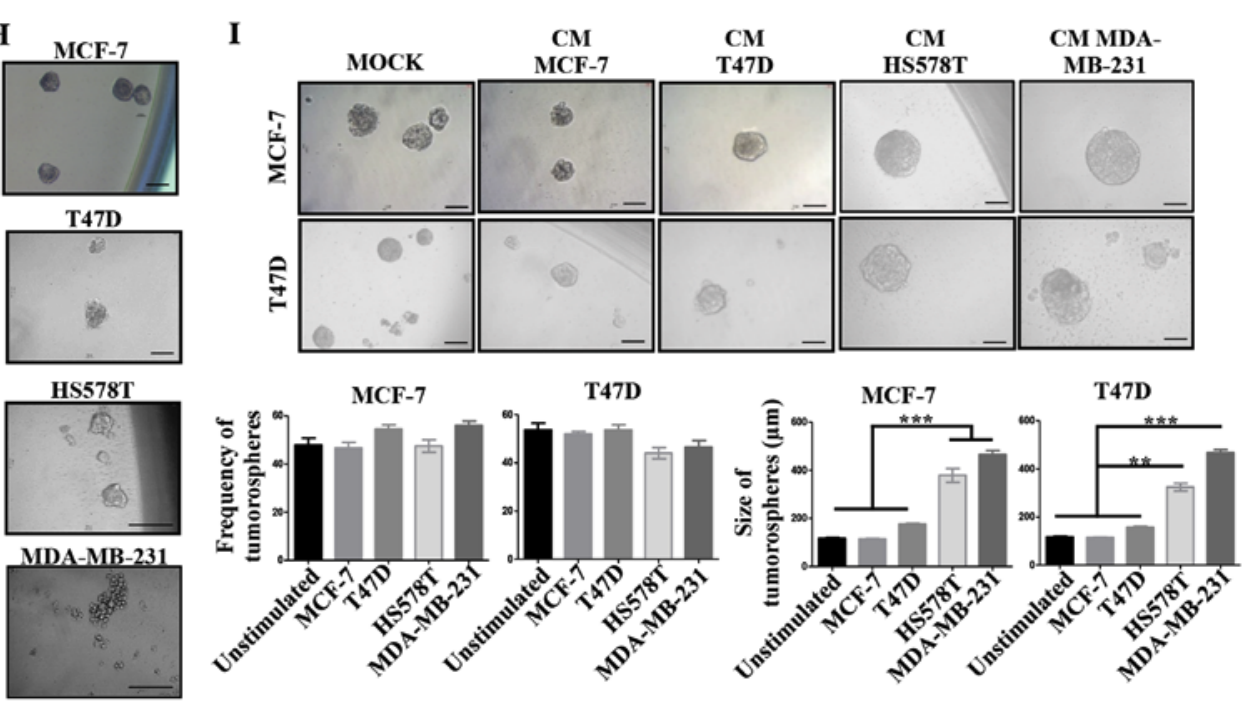

Figure 5. Continued. (E-I) The induced-invasive phenotype correlates with acquisition of stemness markers. Analysis of Oct-4 and Sox-2 IODs is shown for MCF-7 (E) and T47D (F) cells. (G) Sox-2 was also examined by FACS; the upper panels show representative images of cell density plots, while the frequency of Sox-2 positive cells and the MFI of Sox-2 expression are graphed below. $(\mathrm{H})$ The intrinsic sphere forming efficiency of the BrC cell lines was analyzed in ultra-low attachment plates, and (I) after induction of the invasive phenotype in MCF-7 and T47D cells. Plots of the frequency and size of the tumorspheres are shown. Data represent the mean \pm SEM from 3 independent experiments, representative images are shown. ${ }^{*} \mathrm{P}<0.05,{ }^{* * *} \mathrm{P}<0.01$ and ${ }^{* * * *} \mathrm{P}<0.001$. Scale bars indicate $50 \mu \mathrm{m}$ for MCF-7 and T47D, and $100 \mu \mathrm{m}$ for HS578T and MDA-MB-231 tumorspheres (H and I). Magnification, $\mathrm{x} 400$. 


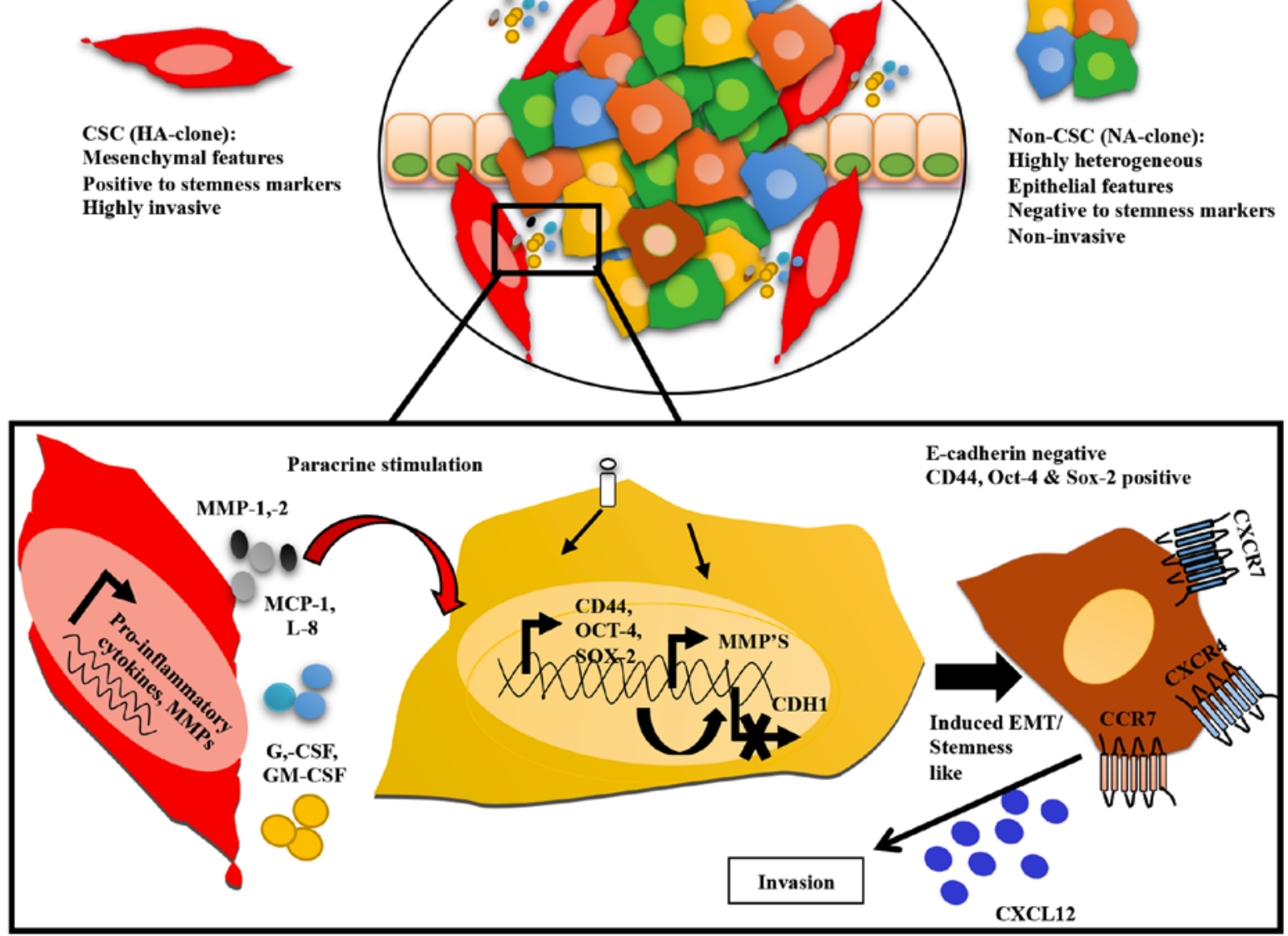

Figure 6. Working model. $\mathrm{BrC}$ is a heterogeneous disease with extensive intra-tumoral clonal diversity in which paracrine communication between different tumor clones influences the aggressive behavior of the tumor. Pro-inflammatory mediators, such as MCP-1, IL-8, GM-CSF and G-CSF, secreted by highly aggressive (HA) tumor clones have the potential to activate signaling pathways associated with aggressive behavior in non-aggressive (NA) clones. These paracrine intra-clonal communication results in the formation of populations with particular transcriptional profiles favoring processes related to the partial epithelial to mesenchymal transition (loss of E-cadherin but no gain of vimentin), stemness and invasion. Induced cells with acquired EMT/stemness like and invasion potential concur with upregulation of chemokine receptors, responding to $\mathrm{HA}-\mathrm{BrC}$ (or other tumor stromal cells) secreted chemokines. In addition, paracrine secretion of metalloproteinases (MMPs) would facilitate the invasion of induced-clones trough degradation of the extracellular matrix. This mechanism may be critical to shape the tumor clinical outcome influencing metastasis, chemoresistance and disease relapse.

axis is widely documented as a potent promoter of invasion and metastasis in several types of cancer, and most likely also has an important role in the promotion of invasion of the induced-NA BrC cells $(40,41)$.

Tumors with high density of CSCs are characterized by high expression of inflammatory mediators $(42,43)$. We found that HA-BrC cell lines secret high levels of G-CSF, GM-CSF, MCP-1 and IL-8. Of them, MCP-1 and IL-8 were potent inducers of invasiveness of MCF-7 cells, and G-CSF, GM-CSF, IL-8 and MCP-1 of T47D cells. MCP-1 and IL-8 are considered critical pro-tumoral cytokines mainly because of their capacity to shape the TME by attracting immune cell populations $(44,45)$. We have also observed that aggressive tumor cells are particularly proficient to attract monocytes/ macrophages through secretion of GM-CSF and MCP-1, and monocyte/macrophage co-cultivation with tumor cells further increase secretion of IL-8 and IL-1 $\beta$ (46). Importantly, this study supports the capacity of tumor cells to secrete pro-inflammatory cytokines promoting stemness and invasion independent of other cellular components of the tumor stroma. In agreement, other studies support that autocrine overexpression of MCP-1 and IL-8 promotes tumor cell proliferation, migration, chemoresistance, metastasis and disease relapse $(27,28,47)$. In patients with breast and prostate cancers MCP-1 overexpression correlates with poor prognosis $(48,49)$, and autocrine regulation of MCP-1 is associated with EMT, immunosuppression and metastasis (50). Blocking MCP-1 in triple-negative $\mathrm{BrC}$ decreased the frequency and self-renewal potential of breast CSCs (51). Other studies support an association between IL-8, MCP-1 and MMPs, and induction of CSCs and metastasis $(24,51,52)$. Of note, we also observed high levels of MMP-1 and MMP-2 secreted by HA-BrC cells.

In conclusion, our results support a model in which in a heterogeneous disease like cancer, highly aggressive tumor clones communicate with less aggressive clones through paracrine mediators, such as IL-8, MCP-1, G-CSF, GM-CSF and MMPs, transferring aggressive features in line with a CSC-like phenotype and increased potential for invasion (Fig. 6). Although TGF- $\beta$ remains the best-understood signal accountable for tumor cell plasticity, we could not find TGF- $\beta$ participation in the inducible-invasive phenotype. Further studies should look into these pro-inflammatory 
factors in carefully staged $\mathrm{BrC}$ patients, comparing metastatic tumors against non-metastatic tumors or comparing other relevant clinical parameters, such as resistance to treatment, disease relapse and overall survival. We were unable to obtain the clinical data in our series of patients. Almost all the patients included in this study were classified as stage I and II, with only three patients in stage III and none in stage IV. Understanding the mechanisms guiding intra-tumoral heterogeneity, cell plasticity and tumor aggressiveness will provide better targets for diagnosis, prognosis and therapeutic strategies.

\section{Acknowledgements}

N.A.E.-S. is a doctoral student from Programa de Doctorado en Ciencias Biomédicas, Universidad Nacional Autónoma de México (UNAM) and received fellowship 231663 from CONACYT. N.A.E.-S. also acknowledges the financial support provided by the Mexican Institute of Social Security (IMSS, ref. 2010-017).J.C.B. acknowledges the scholarship provided by CONACyT and IMSS. This work was supported by CONACyT FONSEC SSA/IMSS/ISSSTE Project no. 233061 and by Fondo de Apoyo a la investigación, Hospital Infantil de México Federico Gómez (Project no. HIM-2014-053) to E.M.F.-P. The authors wish to thank Dr Abigail Morales Sánchez for her input during the statistical analysis.

\section{References}

1. Bray F, Ren JS, Masuyer E and Ferlay J: Global estimates of cancer prevalence for 27 sites in the adult population in 2008. Int J Cancer 132: 1133-1145, 2013.

2. Ferlay J, Soerjomataram I, Dikshit R, Eser S, Mathers C, Rebelo M, Parkin DM, Forman D and Bray F: Cancer incidence and mortality worldwide: Sources, methods and major patterns in GLOBOCAN 2012. Int J Cancer 136: E359-E386, 2015.

3. Sørlie T, Perou CM, Tibshirani R, Aas T, Geisler S, Johnsen H, Hastie T, Eisen MB, van de Rijn M, Jeffrey SS, et al: Gene expression patterns of breast carcinomas distinguish tumor subclasses with clinical implications. Proc Natl Acad Sci USA 98: 10869-10874, 2001.

4. Ng CKY, Pemberton HN and Reis-Filho JS: Breast cancer intratumor genetic heterogeneity: Causes and implications. Expert Rev Anticancer Ther 12: 1021-1032, 2012.

5. Chimal-Ramírez GK, Espinoza-Sánchez NA and FuentesPananá EM: Protumor activities of the immune response: Insights in the mechanisms of immunological shift, oncotraining, and oncopromotion. J Oncol 2013: 835956, 2013.

6. Miller FR, Miller BE and Heppner GH: Characterization of metastatic heterogeneity among subpopulations of a single mouse mammary tumor: Heterogeneity in phenotypic stability. Invasion Metastasis 3: 22-31, 1983.

7. Calbo J, van Montfort E, Proost N, van Drunen E, Beverloo HB, Meuwissen R and Berns A: A functional role for tumor cell heterogeneity in a mouse model of small cell lung cancer. Cancer Cell 19: 244-256, 2011

8. Wu M, Pastor-Pareja JC and Xu T: Interaction between Ras(V12) and scribbled clones induces tumour growth and invasion. Nature 463: 545-548, 2010.

9. Cleary AS, Leonard TL, Gestl SA and Gunther EJ: Tumour cell heterogeneity maintained by cooperating subclones in Wnt-driven mammary cancers. Nature 508: 113-117, 2014.

10. Bose D, Zimmerman LJ, Pierobon M, Petricoin E, Tozzi F, Parikh A, Fan F, Dallas N, Xia L, Gaur P, et al: Chemoresistant colorectal cancer cells and cancer stem cells mediate growth and survival of bystander cells. Br J Cancer 105: 1759-1767, 2011.

11. Mukherjee S, Manna A, Bhattacharjee P, Mazumdar M, Saha S, Chakraborty S, Guha D, Adhikary A, Jana D, Gorain M, et al: Non-migratory tumorigenic intrinsic cancer stem cells ensure breast cancer metastasis by generation of CXCR4(+) migrating cancer stem cells. Oncogene 35: 4937-4948, 2016.
12. Chaffer CL, Marjanovic ND, Lee T, Bell G, Kleer CG, Reinhardt F, D'Alessio AC, Young RA and Weinberg RA: Poised chromatin at the ZEB1 promoter enables breast cancer cell plasticity and enhances tumorigenicity. Cell 154: 61-74, 2013.

13. Shackleton M, Quintana E, Fearon ER and Morrison SJ: Heterogeneity in cancer: Cancer stem cells versus clonal evolution. Cell 138: 822-829, 2009.

14. Kalluri R and Weinberg RA: The basics of epithelial-mesenchymal transition. J Clin Invest 119: 1420-1428, 2009.

15. Massagué J: TGFbeta in cancer. Cell 134: 215-230, 2008

16. Mani SA, Guo W, Liao MJ, Eaton EN, Ayyanan A, Zhou AY, Brooks M, Reinhard F, Zhang CC, Shipitsin M, et al: The epithelial-mesenchymal transition generates cells with properties of stem cells. Cell 133: 704-715, 2008.

17. Santisteban M, Reiman JM, Asiedu MK, Behrens MD, Nassar A, Kalli KR, Haluska P, Ingle JN, Hartmann LC, Manjili MH, et al: Immune-induced epithelial to mesenchymal transition in vivo generates breast cancer stem cells. Cancer Res 69: 2887-2895, 2009.

18. Aktas B, Tewes M, Fehm T, Hauch S, Kimmig R and Kasimir-Bauer S: Stem cell and epithelial-mesenchymal transition markers are frequently overexpressed in circulating tumor cells of metastatic breast cancer patients. Breast Cancer Res 11: R46, 2009.

19. Lacroix M and Leclercq G: Relevance of breast cancer cell lines as models for breast tumours: An update. Breast Cancer Res Treat 83: 249-289, 2004.

20. McAllister SS and Weinberg RA: The tumour-induced systemic environment as a critical regulator of cancer progression and metastasis. Nat Cell Biol 16: 717-727, 2014.

21. Luker KE and Luker GD: Functions of CXCL12 and CXCR4 in breast cancer. Cancer Lett 238: 30-41, 2006.

22. Ali S and Lazennec G: Chemokines: Novel targets for breast cancer metastasis. Cancer Metastasis Rev 26: 401-420, 2007.

23. García-Rocha R, Moreno-Lafont M, Mora-García ML, Weiss-Steider B, Montesinos JJ, Piña-Sánchez P and Monroy-García A: Mesenchymal stromal cells derived from cervical cancer tumors induce TGF- $\beta 1$ expression and IL-10 expression and secretion in the cervical cancer cells, resulting in protection from cytotoxic $\mathrm{T}$ cell activity. Cytokine 76: 382-390, 2015.

24. Chimal-Ramírez GK, Espinoza-Sánchez NA and FuentesPananá EM: A role for the inflammatory mediators Cox-2 and metalloproteinases in cancer stemness. Anticancer Agents Med Chem 15: 837-855, 2015.

25. Mukaida N, Sasaki S and Baba T: Chemokines in cancer development and progression and their potential as targeting molecules for cancer treatment. Mediators Inflamm 2014: 170381, 2014.

26. Aliper AM, Frieden-Korovkina VP, Buzdin A, Roumiantsev SA and Zhavoronkov A: A role for G-CSF and GM-CSF in nonmyeloid cancers. Cancer Med 3: 737-746, 2014.

27. Soria G, Ofri-Shahak M, Haas I, Yaal-Hahoshen N, Leider-Trejo L, Leibovich-Rivkin T, Weitzenfeld P, Meshel T, Shabtai E, Gutman M, et al: Inflammatory mediators in breast cancer: Coordinated expression of TNF $\alpha$ \& IL-1 $\beta$ with CCL2 \& CCL5 and effects on epithelial-to-mesenchymal transition. BMC Cancer 11: 130, 2011.

28. Schadendorf D, Möller A, Algermissen B, Worm M, Sticherling $M$ and Czarnetzki BM: IL-8 produced by human malignant melanoma cells in vitro is an essential autocrine growth factor. J Immunol 151: 2667-2675, 1993.

29. Al-Hajj M, Wicha MS, Benito-Hernandez A, Morrison SJ and Clarke MF: Prospective identification of tumorigenic breast cancer cells. Proc Natl Acad Sci USA 100: 3983-3988, 2003.

30. Schoenhals M, Kassambara A, De Vos J, Hose D, Moreaux J and Klein B: Embryonic stem cell markers expression in cancers. Biochem Biophys Res Commun 383: 157-162, 2009.

31. Weiswald LB, Bellet D and Dangles-Marie V: Spherical cancer models in tumor biology. Neoplasia 17: 1-15, 2015.

32. Manuel Iglesias J, Beloqui I, Garcia-Garcia F, Leis O, VazquezMartin A, Eguiara A, Cufi S, Pavon A, Menendez JA, Dopazo J, et al: Mammosphere formation in breast carcinoma cell lines depends upon expression of E-cadherin. PLoS One 8: e77281, 2013.

33. Greaves M and Maley CC: Clonal evolution in cancer. Nature 481: 306-313, 2012.

34. Marusyk A, Tabassum DP, Altrock PM, Almendro V, Michor F and Polyak K: Non-cell-autonomous driving of tumour growth supports sub-clonal heterogeneity. Nature 514: 54-58, 2014. 
35. Kasimir-Bauer S, Hoffmann O, Wallwiener D, Kimmig R and Fehm T: Expression of stem cell and epithelial-mesenchymal transition markers in primary breast cancer patients with circulating tumor cells. Breast Cancer Res 14: R15, 2012.

36. Oon ML, Thike AA, Tan SY and Tan PH: Cancer stem cell and epithelial-mesenchymal transition markers predict worse outcome in metaplastic carcinoma of the breast. Breast Cancer Res Treat 150: 31-41, 2015.

37. McFarlane S, Coulter JA, Tibbits P, O'Grady A, McFarlane C, Montgomery N, Hill A, McCarthy HO, Young LS, Kay EW, et al: CD44 increases the efficiency of distant metastasis of breast cancer. Oncotarget 6: 11465-11476, 2015.

38. Wang D, Lu P, Zhang H, Luo M, Zhang X, Wei X, Gao J, Zhao Z and Liu C: Oct-4 and Nanog promote the epithelial-mesenchymal transition of breast cancer stem cells and are associated with poor prognosis in breast cancer patients. Oncotarget 5: 10803-10815, 2014.

39. Ben-Porath I, Thomson MW, Carey VJ, Ge R, Bell GW, Regev A and Weinberg RA: An embryonic stem cell-like gene expression signature in poorly differentiated aggressive human tumors. Nat Genet 40: 499-507, 2008.

40. Singh AK, Arya RK, Trivedi AK, Sanyal S, Baral R, Dormond O, Briscoe DM and Datta D: Chemokine receptor trio: CXCR3, CXCR4 and CXCR7 crosstalk via CXCL11 and CXCL12. Cytokine Growth Factor Rev 24: 41-49, 2013.

41. Guo F, Wang Y, Liu J, Mok SC, Xue F and Zhang W: CXCL12/ CXCR4: A symbiotic bridge linking cancer cells and their stromal neighbors in oncogenic communication networks. Oncogene 35: 816-826, 2016

42. Liu H, Patel MR, Prescher JA, Patsialou A, Qian D, Lin J, Wen S, Chang YF, Bachmann MH, Shimono Y, et al: Cancer stem cells from human breast tumors are involved in spontaneous metastases in orthotopic mouse models. Proc Natl Acad Sci USA 107: 18115-18120, 2010.

43. Sheridan C, Kishimoto H, Fuchs RK, Mehrotra S, BhatNakshatri P, Turner CH, Goulet R Jr, Badve S and Nakshatri H: CD $44^{+} / \mathrm{CD} 24^{-}$breast cancer cells exhibit enhanced invasive properties: An early step necessary for metastasis. Breast Cancer Res8: R59, 2006.
44. Palena C, Hamilton DH and Fernando RI: Influence of IL-8 on the epithelial-mesenchymal transition and the tumor microenvironment. Future Oncol 8: 713-722, 2012.

45. Chen W, Gao Q, Han S, Pan F and Fan W: The CCL2/CCR2 axis enhances IL-6-induced epithelial-mesenchymal transition by cooperatively activating STAT3-Twist signaling. Tumour Biol 36: 973-981, 2015.

46. Espinoza-Sánchez NA, Chimal-Ramírez GK, Mantilla A and Fuentes-Pananá EM: IL-1 $\beta$, IL-8 and matrix metalloproteinases $-1,-2$ and -10 are enriched upon monocyte-breast cancer cell co-cultivation in a Matrigel-based three dimensional system. Front Immunol 8, 205, 2017.

47. Ning Y, Manegold PC, Hong YK, Zhang W, Pohl A, Lurje G, Winder T, Yang D, LaBonte MJ, Wilson PM et al: Interleukin-8 is associated with proliferation, migration, angiogenesis and chemosensitivity in vitro and in vivo in colon cancer cell line models. Int J Cancer 128: 2038-2049, 2011.

48. Saji H, Koike M, Yamori T, Saji S, Seiki M, Matsushima K and Toi M: Significant correlation of monocyte chemoattractant protein-1 expression with neovascularization and progression of breast carcinoma. Cancer 92: 1085-1091, 2001.

49. Lu Y, Cai Z, Xiao G, Liu Y, Keller ET, Yao Z and Zhang J: CCR2 expression correlates with prostate cancer progression. J Cell Biochem 101: 676-685, 2007.

50. Kudo-Saito C, Shirako H, Ohike M, Tsukamoto N and Kawakami Y: CCL2 is critical for immunosuppression to promote cancer metastasis. Clin Exp Metastasis 30: 393-405, 2013.

51. Fang WB, Yao M, Brummer G, Acevedo D, Alhakamy N, Berkland $\mathrm{C}$ and Cheng N: Targeted gene silencing of CCL2 inhibits triple negative breast cancer progression by blocking cancer stem cell renewal and M2 macrophage recruitment. Oncotarget 7: 49349-49367, 2016.

52. Velasco-Velázquez MA, Popov VM, Lisanti MP and Pestell RG: The role of breast cancer stem cells in metastasis and therapeutic implications. Am J Pathol 179: 2-11, 2011. 